\title{
Blue light exposure in vitro causes toxicity to trigeminal neurons and glia through increased superoxide and hydrogen peroxide generation
}

\author{
V. Marek ${ }^{\mathrm{a}, \mathrm{b}, *}$, A. Potey ${ }^{\mathrm{b}}$, A. Réaux-Le-Goazigo ${ }^{\mathrm{b}}, \mathrm{E}$. Reboussin ${ }^{\mathrm{b}}$, A. Charbonnier ${ }^{\mathrm{b}}$, T. Villette $^{\mathrm{a}}$, \\ C. Baudouin ${ }^{\mathrm{b}, \mathrm{c}, \mathrm{e}}$, W. Rostène ${ }^{\mathrm{b}}$, A. Denoyer ${ }^{\mathrm{b}, \mathrm{c}, \mathrm{d}}, \mathrm{S}$. Mélik Parsadaniantz \\ ${ }^{\text {a }} R \& D$, Essilor International, Paris, France \\ ${ }^{\mathrm{b}}$ Sorbonne Université, INSERM, CNRS, Institut de la Vision, Paris, France \\ ${ }^{\text {c } C e n t r e ~ H o s p i t a l i e r ~ N a t i o n a l e ~ d ' O p h t a l m o l o g i e ~ d e s ~ Q u i n z e-V i n g t s, ~ P a r i s, ~ F r a n c e ~}$ \\ ${ }^{\mathrm{d}}$ CHU Robert Debré, Université Reims Champagne-Ardenne, Reims, France \\ ${ }^{\mathrm{e}}$ Versailles-Saint-Quentin-en-Yvelines Université, Versailles, France
}

\begin{abstract}
A B S T R A C T
Keywords:

Blue light

Trigeminal neural cells

Glial cells

Non-visual opsins

Neurophototoxicity

Today the noxiousness of blue light from natural and particularly artificial (fluorescent tubes, LED panels, visual displays) sources is actively discussed in the context of various ocular diseases. Many of them have an important neurologic component and are associated with ocular pain. This neuropathic signal is provided by nociceptive neurons from trigeminal ganglia. However, the phototoxicity of blue light on trigeminal neurons has not been explored so far. The aim of the present in vitro study was to investigate the cytotoxic impact of various wavebands of visible light $(410-630 \mathrm{~nm})$ on primary cell culture of mouse trigeminal neural and glial cells.

Three-hour exposure to narrow wavebands of blue light centered at 410,440 and $480 \mathrm{~nm}$ of average $1.1 \mathrm{~mW} /$ $\mathrm{cm}^{2}$ irradiance provoked cell death, altered cell morphology and induced oxidative stress and inflammation. These effects were not observed for other tested visible wavebands. We observed that neurons and glial cells processed the light signal in different manner, in terms of resulting superoxide and hydrogen peroxide generation, inflammatory biomarkers expression and phototoxic mitochondrial damage. We analyzed the pathways of photic signal reception, and we proposed that, in trigeminal cells, in addition to widely known mitochondriamediated light absorption, light could be received by means of non-visual opsins, melanopsin (opn4) and neuropsin (opn5). We also investigated the mechanisms underlying the observed phototoxicity, further suggesting an important role of the endoplasmic reticulum in neuronal transmission of blue-light-toxic message. Taken together, our results give some insight into circuit of tangled pain and photosensitivity frequently observed in patients consulting for these ocular symptoms.
\end{abstract}

\section{Introduction}

Ambient light from natural (sun) and artificial (fluorescent tubes, LED panels, visual displays) luminous sources is recognized as an aggravating factor for various ocular diseases [1]. Since artificial sources and particularly digital screens highly emit in the blue spectrum, the issue of blue light noxiousness has been much discussed [2,3]. In western countries, one of the main reason for visiting an ophthalmologist is exacerbated photosensitivity and ocular symptoms of discomfort in various luminous conditions [4-7] like being in front of monitors [8-11]. So far a lot of studies have already investigated the UV and blue-light photodamage related to ocular diseases such as keratitis, cataract, and retinal degeneration [12-16]. Similarly, the interest in dry-eye-related phototoxicity on the ocular surface is constantly growing [17-22].

Many eye diseases that are discussed in relation to light damage have a neurologic component, and are mostly associated with ocular pain $[6,23,24]$. In higher vertebrates, this neuropathic signal arises from a particular set of nociceptive neurons located in the trigeminal ganglion (TG) whose axons travel to the eye through the trigeminal ophthalmic nerve and its distal branches [25]. Thus, it could be supposed that blue light might have a direct impact on these nociceptive

\footnotetext{
Abbreviations and conventional signs: AraC, antimitotic treatment (Cytosine-1- $\beta$-D-arabinofuranoside); DED, dry eye disease; ER, endoplasmic reticulum; $\lambda \uparrow$, ex-

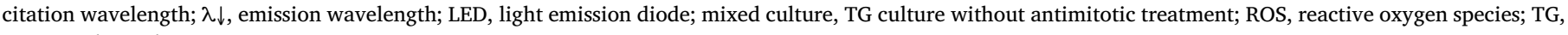
trigeminal ganglion

* Correspondence to: Essilor International R\&D, 13 rue Moreau, 75012 Paris, France.

E-mail address: nika.marek@gmail.com (V. Marek).
} 
cells that are not originally related to vision though. This issue is even more relevant since a recent study reported the intrinsic photosensitivity of trigeminal ganglia [26]. However, to the best of our knowledge, no thorough study about the phototoxicity in trigeminal neural cells has been published so far.

We previously reported the blue light phototoxicity onto the ocular surface in an in vitro model of dry eye disease (DED) [17] and in vivo, the implication of trigeminal pain-related pathways in ocular inflammation [27]. In the present work, we demonstrate in vitro the major cell death and oxidative stress related cytotoxic impact of blue light on primary cultured neural cells from mouse trigeminal ganglia. On both neurons and glial cells, we detail the ways of light signal reception and the subsequent pathways of phototoxic message transmission. On the basis of our experimental data, we hypothesize about potential implication of melanopsin and neuropsin in trigeminal phototoxicity.

\section{Results}

\subsection{Blue light decreases neural cell viability and modifies neuronal morphology}

The shortest-wavelength $410 \mathrm{~nm}$ blue light significantly decreased trigeminal neural cell viability $(0.43 \pm 0.06, \quad \mathrm{q}<0.0001$, $\mathrm{p}<0.0001$ ). Antimitotic treatment (AraC) amplified the observed impact $(0.15 \pm 0.07, \mathrm{q}<0.0001, \mathrm{p}<0.0001)$ revealing it also for $440 \mathrm{~nm}$ exposure $(0.78 \pm 0.12, \mathrm{q}=0.0110, \mathrm{p}=0.0052$ when compared to the non-AraC dark control) (Fig. 1A). Accordingly, for blue wavebands, the rate of fluorescent signals generated by cell death markers significantly increased (YO-PRO for apoptosis: normal conditions $-10.48 \pm 0.88, \mathrm{q}<0.0001, \mathrm{p}<0.0001$ for $410 \mathrm{~nm}$, antimitotic treatment $-28.25 \pm 4.01, \mathrm{q}<0.0001, \mathrm{p}<0.0001 ; 1.83 \pm 0.20$, $\mathrm{q}<0.0001, \mathrm{p}<0.0001$ and $1.53 \pm 0.19, \mathrm{q}=0.0037, \mathrm{p}=0.0035$ for 410,440 and $480 \mathrm{~nm}$, respectively; PI for necrosis: $8.64 \pm 2.80$, q $=0.0065, \mathrm{p}=0.0015$ and $17.82 \pm 4.60, \mathrm{q}<0.0001, \mathrm{p}<0.0001$ for $410 \mathrm{~nm}$ in normal and antimitotic conditions, respectively) (Fig. 1C,D). In addition, the rate of DAPI, a DNA intercalant that can therefore be considered as another marker of apoptosis, increased for $410 \mathrm{~nm}$ illumination as well $(1.37 \pm 0.17, \mathrm{q}=0.0036, \mathrm{p}=0.0008$ and $1.29 \pm 0.13, \mathrm{q}=0.0079, \mathrm{p}=0.0019$ for $410 \mathrm{~nm}$ in normal and antimitotic conditions, respectively) (Fig. 1B). These results were confirmed by microscopic observations for YO-PRO and PI (Fig. 1E,F). Interestingly, the ratio between apoptotic and necrotic signals did not show a significant prevalence of any of them (Fig. 1G). Indeed, for $410 \mathrm{~nm}$ illumination in merge representation, most of detected dying cells exhibited white fluorescent signal, i.e. the sum of red (PI), green (YO-PRO) and blue (DAPI) stainings, meaning that these cells exhibited both necrotic and apoptotic processes (Fig. 1H).

These data were corroborated by immunocytological studies. First, blue-light-induced cell death was confirmed by GADD153 antibody staining that revealed both growth arrest and DNA damage. Corresponding fluorescent signal was detected after illumination by $410 \mathrm{~nm}$ in mixed cell culture and by 410,440 and $480 \mathrm{~nm}$ under antimitotic treatment (Fig. 2A). Further, staining with neuronal PAN antibody revealed the decreased number of neuron cell bodies exposed to $410 \mathrm{~nm}$ light as compared to dark control condition (Fig. 2B,C). Moreover, the cell neurites showed more dotted structures, which is also related to neuronal damage [27] (Fig. 2B, S1A). Last, high-content quantitative analysis of acquired images identified that blue light-induced morphological changes were mostly neuronal and not glial ones. Indeed, we found a significant decrease in neuron cell number $(0.38 \pm 0.08, \mathrm{q}<0.0001, \mathrm{p}<0.0001$ and $0.19 \pm 0.03, \mathrm{q}=0.0023$, $\mathrm{p}=0.0005$ for $410 \mathrm{~nm}$ in normal and antimitotic conditions, respectively) (without modifications in cell body area) as well as in total neurite length $(0.67 \pm 0.19, \quad \mathrm{q}=0.0352, \mathrm{p}=0.0084$ and
$0.37 \pm 0.08, \mathrm{q}=0.0042, \mathrm{p}=0.0010$ for $410 \mathrm{~nm}$ in normal and antimitotic conditions, respectively) while the impact on the number of glial cells turned out to be non-significant when compared to the appropriate dark control (Fig. 2C-F).

\subsection{Phototoxicity provokes oxidative stress and inflammation}

We measured the rates of generated $\mathrm{H}_{2} \mathrm{O}_{2}$ and $\mathrm{O}_{2}{ }^{-}$, the two major reactive oxygen species (ROS). In conformity with cell viability and death, oxidative stress level significantly increased after exposure to $410 \mathrm{~nm}$ light $(66.48 \pm 22.64, \mathrm{q}=0.0008, \mathrm{p}=0.0002$ and $7.56 \pm 1.70, \mathrm{q}=0.0027, \mathrm{p}=0.0006$ for $\mathrm{H}_{2} \mathrm{O}_{2}$ and $\mathrm{O}_{2}{ }^{-}$, respectively); the effect was amplified in the presence of $\mathrm{AraC}$ $(150.61 \pm 48.81, \mathrm{q}<0.0001, \mathrm{p}<0.0001$ and $37.77 \pm 10.28$, $\mathrm{q}<0.0001, \mathrm{p}<0.0001$ for $\mathrm{H}_{2} \mathrm{O}_{2}$ and $\mathrm{O}_{2}{ }^{--}$, respectively) (Fig. 3A,B). Moreover, the antimitotic treatment induced an important photosensitivity to 440 and $480 \mathrm{~nm}$ light that did not take place in mixed culture. Cells exposed to these wavebands demonstrated a significant increase in hydrogen peroxidase level (by $25.04 \pm 11.20, q=0.0021$, $\mathrm{p}=0.0020$ and $27.51 \pm 8.82, \mathrm{q}=0.0016, \mathrm{p}=0.0008$ for 440 and $480 \mathrm{~nm}$, respectively) (Fig. 3A). Quantitative measurements of mitochondrial $\mathrm{O}_{2}{ }^{--}$rate were corroborated by microscopic observations (Fig. 3C, S1B). Interestingly, the correspondent fluorescent signal was provided by glial and not by neuronal cells. This observation was confirmed by high-content quantitative analysis (Fig. 3D): most of the cells exhibiting the red staining from superoxide anion were also labeled by anti-glial cell antibody (anti-GFAP) (Fig. 3E).

In addition, we analyzed the mRNA expression of biomarkers implicated in neuronal activation and cellular inflammation. Exposure to $410 \mathrm{~nm}$ provoked a significant increase in ATF3 rate in mixed culture $(1.52 \pm 0.14, \mathrm{q}=0.0257, \mathrm{p}=0.0061)$; cFOS and IL-6 expression increased in both conditions $(1.90 \pm 0.28, \mathrm{q}=0.0232, \mathrm{p}=0.0055$ and $2.34 \pm 0.20, q=0.0023, p=0.0005$ for cFOS and $2.66 \pm 0.40$, $\mathrm{q}<0.0001, \mathrm{p}<0.0001$ and $1.99 \pm 0.33, \mathrm{q}=0.0010, \mathrm{p}=0.0002$ for IL-6, in normal and antimitotic conditions, respectively). Under antimitotic treatment using AraC, CCL2 level significantly increased for $410(2.10 \pm 0.65, q=0.0284, \mathrm{p}=0.0180)$ and also for 480 $(2.30 \pm 0.62, \mathrm{q}=0.0184, \mathrm{p}=0.0058) \mathrm{nm}$ illumination while TGF $\beta 2$ rate not-significantly went down as a nondecreasing function of wavelength (Fig. 4).

\subsection{Pathways of blue light phototoxicity}

To better understand the mechanisms underlying the observed phototoxicity, we investigated the implication of kinase cascade that is known to have an important role in integrating and processing of external signals. In both neurons and glial cells exposed to all the blue wavebands, staining with pERK1/2 antibody revealed an important decrease or even an absence of the correspondent fluorescent signal (Fig. 5A). This result (independent on AraC) revealed that blue light did induce an important deregulation of internal cell signaling processes.

Since we observed an important light-induced superoxide and hydrogen peroxide rate, we then examined the status of mitochondria, the main cellular generator of oxidative stress. In neurons, we did not detect any illumination-related differences in mitochondrial staining (data not shown). In glial cells, however, we observed a qualitative increase of fluorescent signal after exposure to $410 \mathrm{~nm}$ light (Fig. 5B,C).

\subsection{Photoreception}

To investigate whether the culture of cells from trigeminal ganglia possessed any other photoreceptive targets in addition to blue-violet sensitive molecules of the respiratory chain, we looked for the putative role of other pigments by performing immunocytological staining with anti-melanopsin (opn4) and anti-neuropsin (opn5) antibodies. We 
detected melanopsin immuno-reactivity in some sensory neurons for all the light conditions as well as for the dark control (Fig. 6A, S4). As for neuropsin, we observed the correspondent staining in several glial cells after illumination whatever the wavelength. In neurons, we detected the opn5-staining only after exposure to 410,480 and $630 \mathrm{~nm}$ light (Fig. 6C). These results were similar for both mixed and antimitoticallytreated cultures.
A

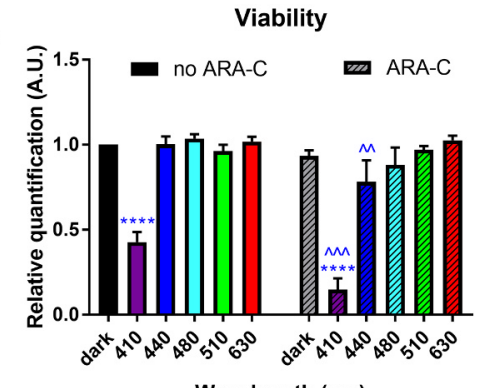

Wavelength $(\mathrm{nm})$

C

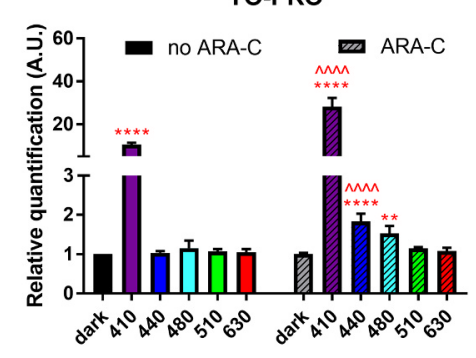

Wavelength $(\mathrm{nm})$
B

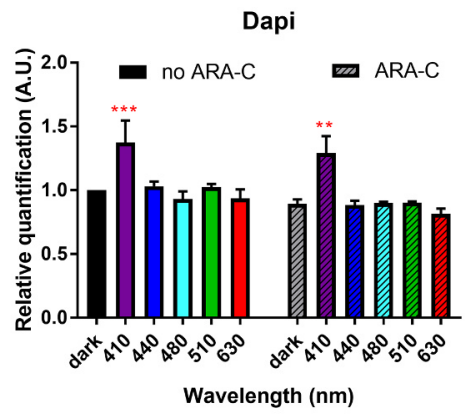

PI

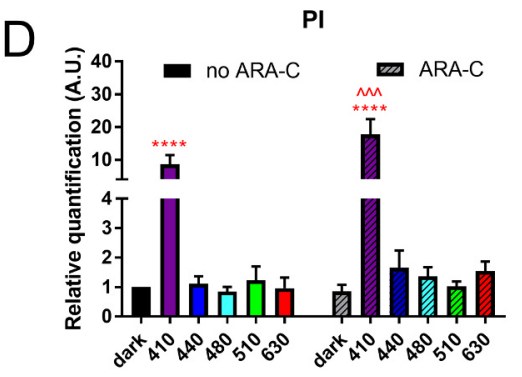

Wavelength $(\mathrm{nm})$
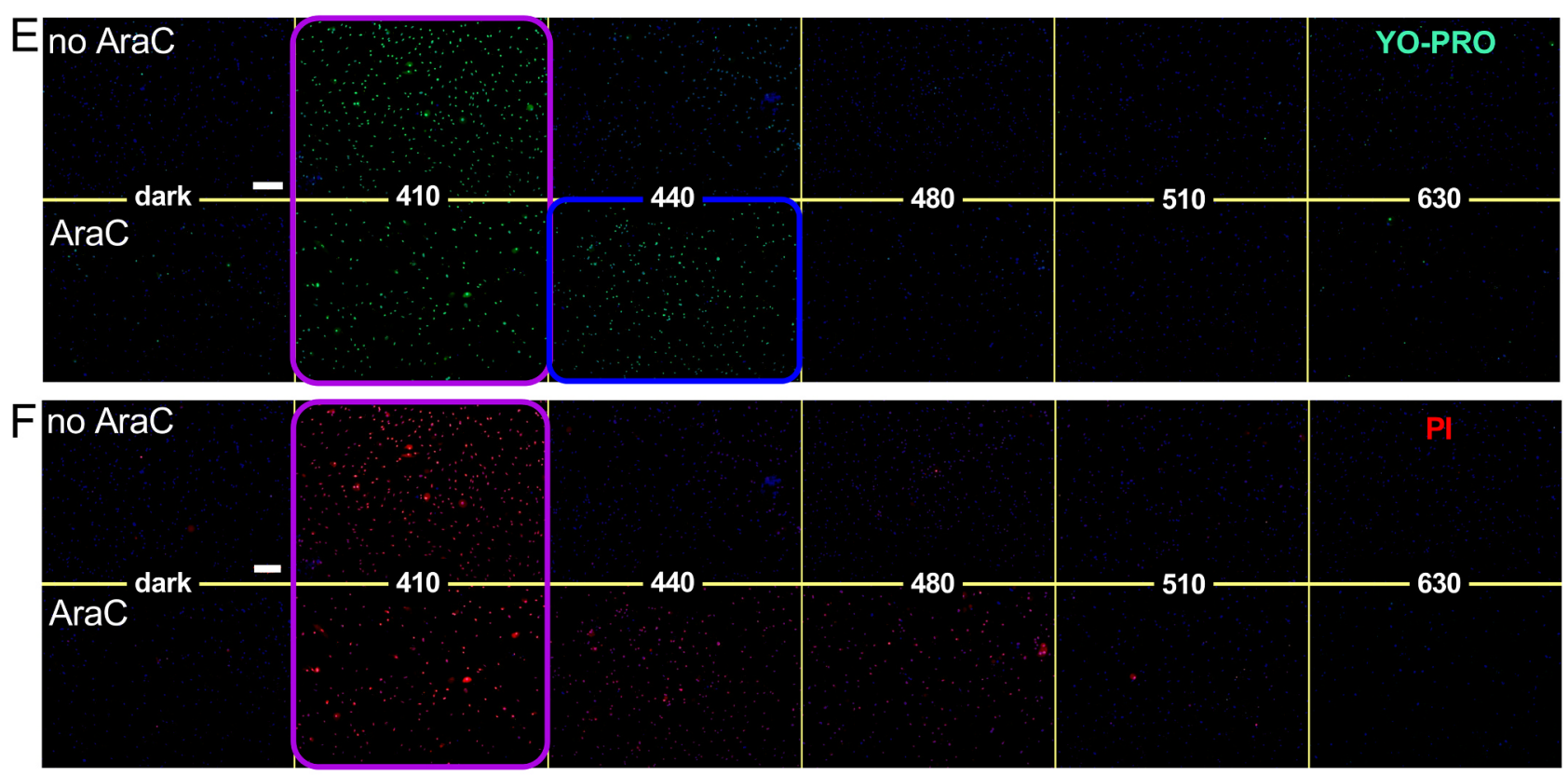

G

YO-PRO/PI ratio

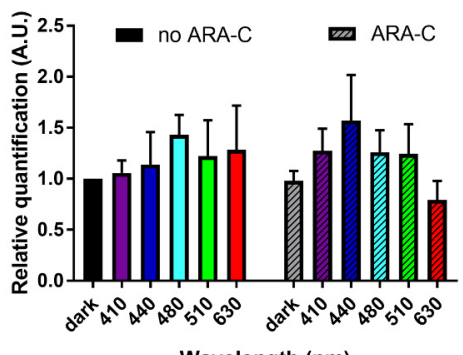

$\mathrm{H}$

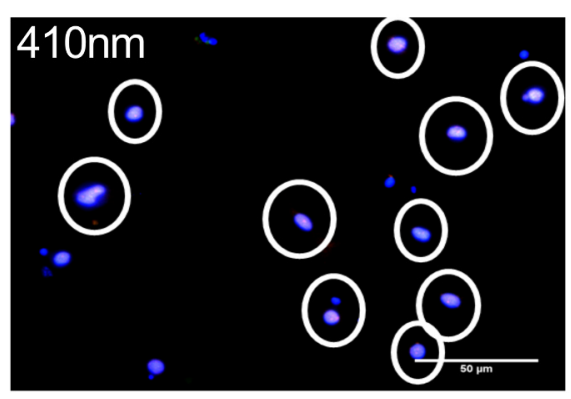




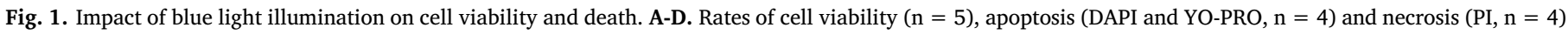

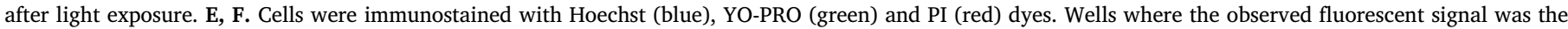

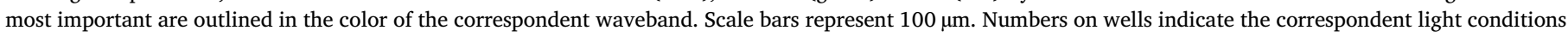

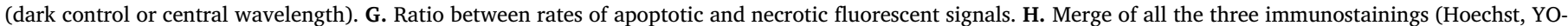

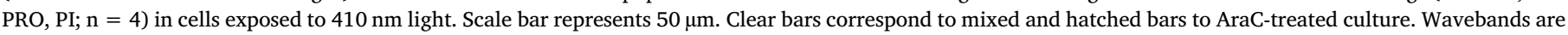

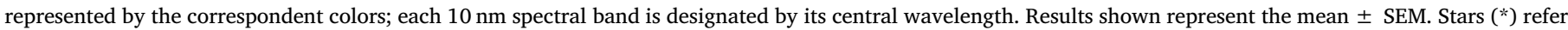

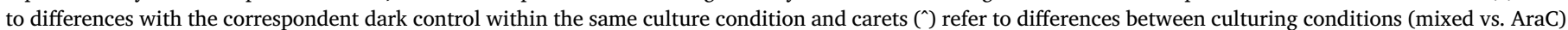

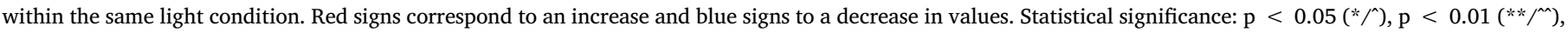
$\mathrm{p}<0.001(* * * / \sim n), \mathrm{p}<0.0001\left(* * * * /{ }^{\wedge \wedge n}\right)$.

\section{Discussion}

Here, we demonstrated in vitro the cytotoxic impact of blue light on primary cell culture of mouse trigeminal cells, further specifying the implication of each cell population through the use of supplementary antimitotic treatment (AraC).

To investigate the wavelength specificity of trigeminal phototoxicity, we explored the impact of narrow $10 \mathrm{~nm}$ wavebands situated within the large blue-green spectrum. We chose the violet $(410 \mathrm{~nm})$ and the blue $(440 \mathrm{~nm})$ wavelengths known to be harmful for the retina $[28,29]$, the turquoise blue $(480 \mathrm{~nm})$ implicated in circadian rhythms [30], the green light $(510 \mathrm{~nm})$ reported to be soothing for photophobic migraineurs $[31,32]$ and also the red light $(630 \mathrm{~nm})$. The part of the plate was kept in the dark for the control condition; the red-illuminated part served as a second control since, to our knowledge, there are no data about any damage from red-light exposure. We used the irradiance range that would approximate the real-life conditions. Indeed, according to recent measurements performed in the R\&D department of Essilor (personal communication), on a sunny slightly cloudy day, we can easily be exposed to $4.89 \mathrm{~mW} / \mathrm{cm}^{2}$ of $380-780 \mathrm{~nm}$ light (entire solar visible spectrum) and to 1.28 and $1.4 \mathrm{~mW} / \mathrm{cm}^{2}$ of its blue $(380-500 \mathrm{~nm})$ and yellow $(500-600 \mathrm{~nm})$ spectral parts respectively (at 10 a.m. in the center Paris at the end of May). We set the illumination time at $3 \mathrm{~h}$ since longer exposures to violet light were too harmful for cells and the shorter ones did not induce any cell death (Fig. S3).

\subsection{Blue light has a harmful impact on entire TG cell population}

All our experiments demonstrated that $410 \mathrm{~nm}$ blue light significantly impacted the primary culture of neural cells, decreasing their viability and increasing cell death. The blue-toxic effects were more important when AraC was applied. Since antimitotic treatment significantly decreased the number of glial cells (Fig. 2F), it reduced neuronal protection and support, thus making neurons more vulnerable to induced stress [33]. Application of AraC allowed to reveal the harmful impacts of two longer blue wavelengths, 440 and $480 \mathrm{~nm}$. Interestingly, $480 \mathrm{~nm}$ light induced an alteration in the rate of apoptosis as assessed by YO-PRO but not in viability. This can be explained by the fact that YO-PRO is an early apoptosis marker implying that cells expressing it might still be alive. Transcription factor GADD153 has been reported as a mediator of apoptosis, of particular potential relevance to neural death $[34,35]$. In our experiments, results of staining with antiGADD153 antibody followed the wavelength-pattern of YO-PRO induction. Interestingly, the majority of dead cells were stained with both apoptotic and necrotic markers meaning that both mechanisms were involved in the effect of blue light-induced cell death.

Oxidative stress and excessive ROS generation are the key factors in the pathogenesis of various ocular surface diseases [36,37]. In the retina and cornea, the phototoxicity of blue light is mostly reported as inducing an oxidative stress $[17,18,28,38]$. As expected, in our experiments, exposure to $410 \mathrm{~nm}$ light increased the rates of hydrogen peroxidase and of mitochondrial superoxide anion. The smaller rate of the latter as compared to the former is probably due to the fact that initially generated $\mathrm{O}_{2}{ }^{-}-$was then transformed into other ROS species [39]. In line with the apoptotic rate, antimitotic treatment amplified the photo-oxidative stress significantly increasing the level of $\mathrm{H}_{2} \mathrm{O}_{2}$ after exposure to 440 and $480 \mathrm{~nm}$ light.

We showed that kinase pathways were implicated in neural phototoxicity. It is well recognized that ERK1/2 plays opposing roles, acting to promote cell survival while also participating in cell death and neurodegeneration [40]. In our experiments, anti-pERK1/2 staining, already reported to be down-regulated by oxidative stress [41], was noticeably decreased after exposure to blue light, in line with $\mathrm{O}_{2}{ }^{--}$and $\mathrm{H}_{2} \mathrm{O}_{2}$ rates measurements. Thus, the phototoxic breakdown of pERK1/2 pro-survival and regulating functions impaired the cellular signaling pathways and defense of neural cells against induced stress. These results are in agreement with those of Kuse et al. who also detected a down-regulation of pERK1/2 in photoreceptor-derived cells exposed to blue LEDs [42].

Oxidative stress is also known to provoke inflammatory response; therefore, the next step was to investigate the mRNA expression of inflammation-related biomarkers. We had previously studied the induced expression of chemokines in the inflamed ocular surface [43] and in trigeminal neurons [27]. Here, we demonstrated that blue-light induced an up-regulation of IL-6 and CCL2, both widely considered as pro-inflammatory cytokines when present at high concentrations [44]. Furthermore, CCL2 is highly implicated in trigeminal nociception $[45,46]$. TGF 32 , one of the major ligands involved in the modulation of cell behavior in ocular tissues [47] and in neural inflammatory responses [48], showed a trend for down-regulation at 410 and $440 \mathrm{~nm}$ exposures. We may ascribe this fact to a probable negative loop regulation that turned on when highly stressed cells produced TGF $\beta 2$ in excess amount as we have previously proposed for the phototoxically-stressed cells of ocular surface [17]. Moreover, TGF $\beta 2$ was reported to have an antiinflammatory role [49], meaning that TGF $\beta 2$ underproduction may be partially responsible for an enhanced phototoxicity. We also investigated the mRNA expression of cFOS and ATF3, markers of neural activation and stress. Normally low, they are rapidly up-regulated in response to neural stimulation [50,51]. Indeed, we detected a significant increase in level of both markers in response to $410 \mathrm{~nm}$ light exposure.

\subsection{Besides the mitochondrial respiratory chain, opsins are also involved in $T G$ cells photosensitivity}

The next question was how the luminous signal was received by neural cell cultures. It is known that photoreception may be linked to molecules of the mitochondrial respiratory chain, such as flavins and cytochrome oxidases, that can directly absorb blue-violet light [52,53]. However, it is not the unique possibility of light reception.

Even if visual photoreceptor cells like rods and cones are absent in trigeminal neural culture, we cannot exclude the possible role of nonvisual receptors. It has been recently reported that small number of neurons in the ophthalmic branch of trigeminal ganglia express melanopsin (opn4) and are intrinsically photosensitive [26]. Moreover, another recent study discovered the previously unrecognized localization of this photopigment in nerve fibers within the cornea [54]. Another non-visual photoreceptor, gaining today an increasing attention, is neuropsin (opn5). Its presence and importance for photoentrainment have been observed in the retina and cornea; however, its precise functions are still unclear $[55,56]$. Thus, we checked for the presence of these non-visual opsins in neural trigeminal culture. 
By means of immunochemistry, we observed the presence of melanopsin in neuronal cell bodies, in line with Delwig et al. [54]. Only some neurons exhibited melanopsin immunoreactivity, in agreement with Matynia et al., according to whom melanopsin is expressed overall in approximately $3 \%$ of TG neurons [26]. It is also in compliance with the fact that neurons innervating the ocular surface represent only $1-5 \%$ of the total number of trigeminal neural cells $[24,57]$. As for neuropsin, we observed its expression only after illumination. It was

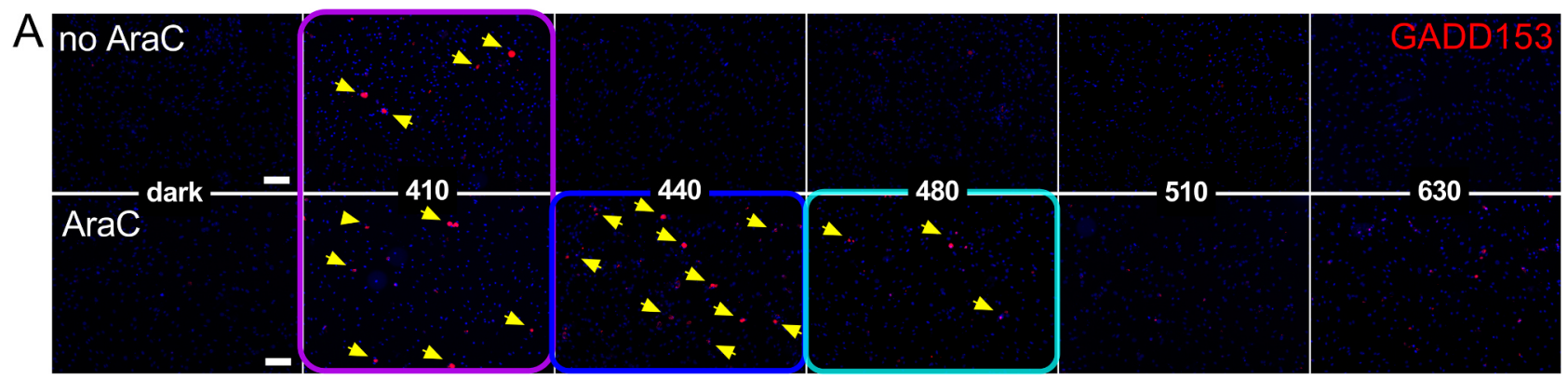

B

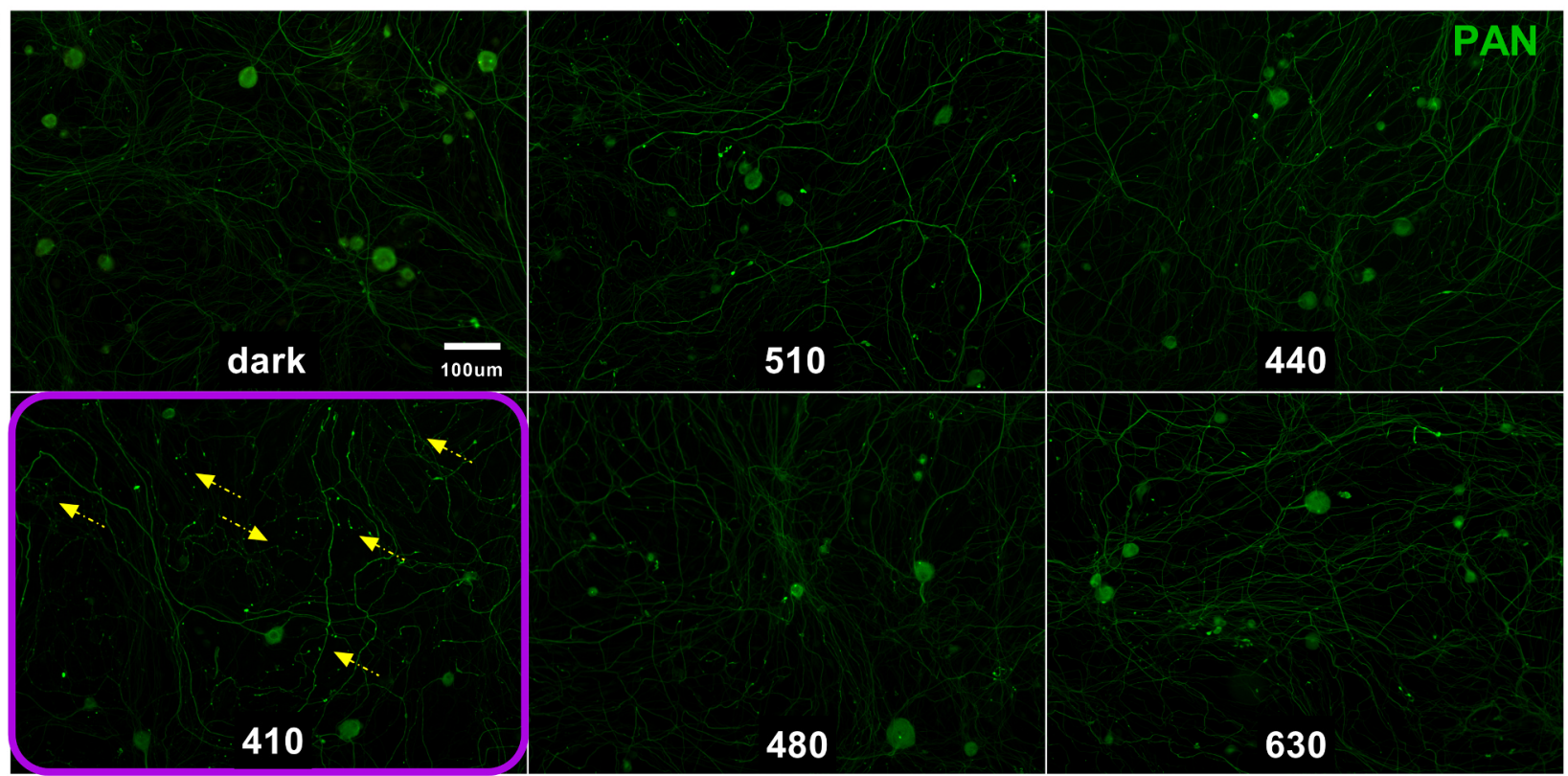

C

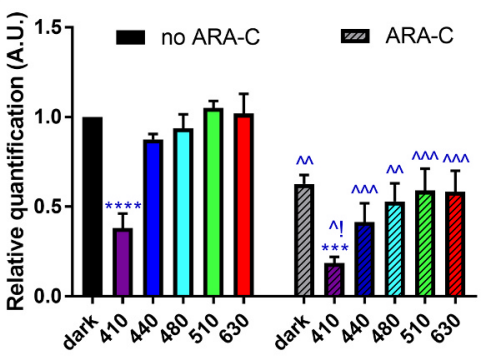

Wavelength $(\mathrm{nm})$

E

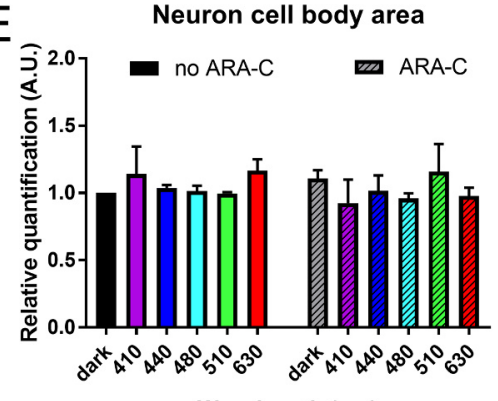

Wavelength $(\mathrm{nm})$

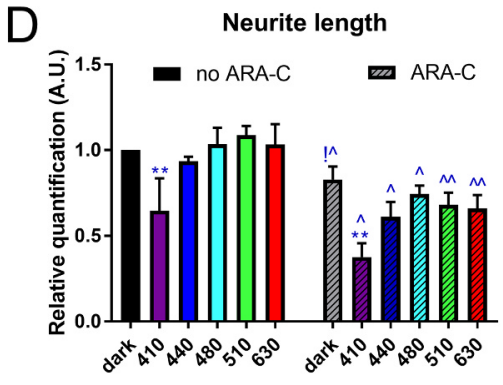

Wavelength $(\mathrm{nm})$

$\mathrm{F}$

Glial cell number

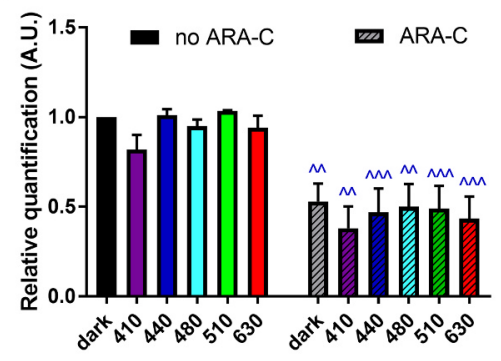

Wavelength (nm) 


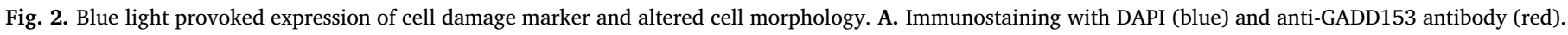

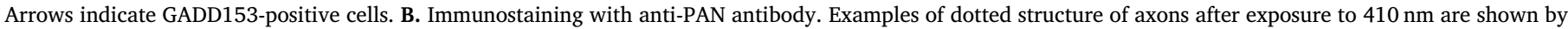

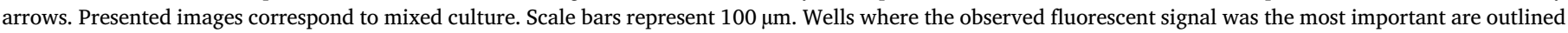

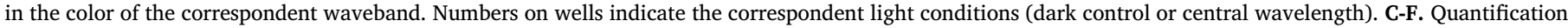

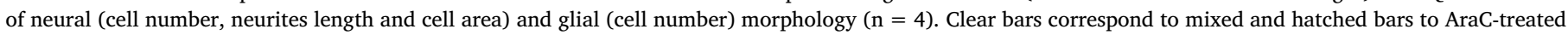

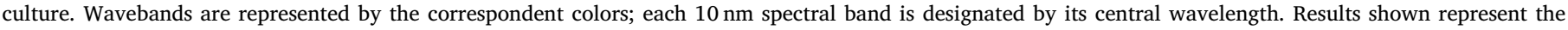

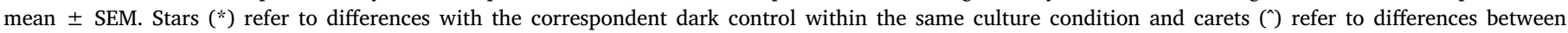

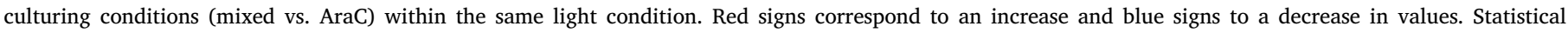
significance: $\mathrm{p}<0.05\left(* /{ }^{\wedge}\right), \mathrm{p}<0.01\left(* * /{ }^{\wedge}\right), \mathrm{p}<0.001\left(* * * /{ }^{\wedge n}\right), \mathrm{p}<0.0001\left(* * * * /{ }^{\wedge \wedge}\right)$.

present in some glial cells, independently on wavelength, and also in neurons, after exposure to 410, 480 and $630 \mathrm{~nm}$ light. According to Buhr et al. [55], neuropsin is sensitive to 370,417 and $475 \mathrm{~nm}$ light. While the last two wavelengths are close to our 410 and $480 \mathrm{~nm}$, they though did not detect any photoentrainment for $630 \mathrm{~nm}$ exposure. However, one should take into account that their study was done on the retina and not on the TG.

Taken together, these results imply that in addition to mitochondria-mediated photoreception system, neural cells may possess another and specific one based on non-visual opsins.

\subsection{Blue light impacts neurons and glial cells in different ways}

ATF3 increased only in mixed cultures, whereas TGB $\beta 2$ (a trend) and CCL2 (significant) levels were altered only under antimitotic treatment, therefore attributing deregulation of the latter two to neurons only.

Immunostaining with anti-neuronal and anti-glial antibodies, corroborated by correspondent quantitative analysis, showed that blue light decreased the number of neuron cell bodies and modified the structure of their neurites while the morphology of glial cells did not significantly change. However, surprisingly, microscopic observations of mitochondrial oxidative stress and correspondent quantitative analysis revealed that $\mathrm{O}_{2}{ }^{--}$was mainly generated by glial cells and not by neurons. To check the mitochondrial status of all the neural cells, we tracked them with a specific fluorescent dye that enters the mitochondria dependently on the proton flux between the outside and inside of the cell. Increased depolarization results in additional dye influx and an increase in fluorescence, while hyperpolarization provides with a decrease in fluorescence [58]. Here again, exposure to $410 \mathrm{~nm}$ light provoked an accumulation of fluorescent signal in mitochondria of glial cells but not of neurons. Thus, neuronal mitochondria did not seem to be affected while there was a blue light induced loss in mitochondrial membrane potential in glial cells. We might ascribe the observed difference in blue light absorption at mitochondrial level to a difference in cytochrome oxidase activity. Indeed, it has been reported that this enzyme demonstrated different properties in neural and non-neural cells; however, the results were somehow contradictory $[59,60]$.

Last, since we observed an increase in $\mathrm{H}_{2} \mathrm{O}_{2}$ rate after exposure to 440 and $480 \mathrm{~nm}$ only in antimitotically-treated cultures, we could hypothesize that neurons were able to be light-sensitive through non-visual opsins' pathway. Indeed, Matsuyama et al. reported the maxima of melanopsin absorption at 446, 467 and $476 \mathrm{~nm}$ exposure [61] thus making it a potential candidate for 440- and 480-nm-phototoxicity transmitter. According to generally accepted statement, the ROS species are mainly generated by mitochondria [62] that turned to be non-impacted in neurons though. However, there might be another possibility to produce $\mathrm{H}_{2} \mathrm{O}_{2}$. Recently, Konno et al. reported that $\mathrm{H}_{2} \mathrm{O}_{2}$ can be generated within the endoplasmic reticulum (ER) but the corresponding mechanisms are still not clear [63]. This possibility is corroborated by our experiments concerning pERK1/2 and GADD153 stainings. Indeed, when protein folding in the ER is impaired due to various physiological and pathological conditions, the organelle has several specific pathways to overcome the stress. The apoptotic one occurs when functions of the ER are severely damaged and may use the pERK1/2 signaling followed by transcriptional activation of GADD153 gene [64].

\subsection{A new proposal of a model for the phototoxic pathway in TG culture}

To sum up, we demonstrated for the first time the blue light phototoxicity in primary culture of trigeminal cells, both in neurons and neuroglia cells. We proposed that non-visual opsins and endoplasmic reticulum have important roles in the cytotoxic process. Taken together, our results might be integrated in the following scheme of bluelight-toxicity trigeminal pathway. Luminous flux is mainly absorbed by glial cells by means of respiratory chain and neuropsin (opn5). Thus induced phototoxicity provokes glial cells death (apoptosis and necrosis) and stress (ATF3) as well as superoxide $\left(\mathrm{O}_{2}{ }^{--}\right)$and hydrogen peroxide $\left(\mathrm{H}_{2} \mathrm{O}_{2}\right)$ over-production and inflammation (IL6). This stress messages then reaches neurons and damages them via the ER pathways with additional oxidative stress and nociceptive message generation (CCL2).

Our findings shed some light on mechanisms underlying the common symptoms of increased sensitivity to daily light frequently accompanied by ocular pain. Thus, this study may open new avenues for the treatment of this disorder, e.g. by using optical devices that would filter out the most toxic blue wavebands for ocular nociception in the given illumination conditions, or by controlling the emission spectra of smartphones and visual displays.

\section{Materials and methods}

\subsection{Cell culture}

Adult male C57BL/6 mice (Janvier Labs, Le Genest Saint Isle, France) were maintained under controlled conditions $\left(22 \pm 1{ }^{\circ} \mathrm{C}\right.$, $60 \pm 10 \%$ relative humidity, $12 / 12 \mathrm{~h} \mathrm{light/dark} \mathrm{cycle,} \mathrm{food} \mathrm{and} \mathrm{water}$ ad libitum). All experiments were approved by the Charles Darwin Ethics Committee for Animal Experimentation (Ce5/2011/05) and carried out in accordance with Directive 2010/63/EU of the European Parliament and the Council of 22 September 2010 and French law (2013/118). Trigeminal ganglia (TGs) were removed from 10 mice and placed in Neurobasal-A without phenol red (i.e., without photosensitizer) buffer. TGs were pooled in $1 \mathrm{ml}$ of fresh Neurobasal-A without phenol red buffer containing $10 \mathrm{mg} / \mathrm{ml}$ of collagenase A and incubated at $37^{\circ} \mathrm{C}$ for $1 \mathrm{~h}$. Then TGs were placed in $1 \mathrm{ml}$ of Trypsine $0.05 \%$ mixed with $50 \mu \mathrm{l}$ of DNAse $50 \mu \mathrm{g} / \mathrm{ml}$ and incubated at $37{ }^{\circ} \mathrm{C}$ for $10 \mathrm{~min}$. TGs were transferred in 'STOP' solution ( $800 \mu \mathrm{l}$ of FBS and $1.2 \mathrm{ml}$ of PBS) and mechanically dissociated using a pipette. Dissociated TGs were pelleted by centrifugation ( $800 \mathrm{rpm}, 10 \mathrm{~min}$ ), the collagenasecontaining supernatant was discarded, and cells were resuspended in Neurobasal-A without phenol red supplemented with $2 \%$ B-27 minus

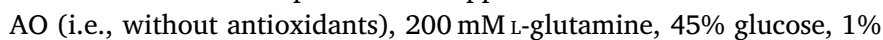
penicillin and $1 \%$ streptomycin. Another mechanical dissociation was performed. Cells were then filtered on a Falcon $70 \mu \mathrm{m}$ cell strainer and centrifuged ( $800 \mathrm{rpm}, 10 \mathrm{~min})$. Supernatant was discarded, cells were resuspended in supplemented Neurobasal-A without phenol red and distributed into 24-well culture plates (CellVis, Mountain View, CA, USA), coated beforehand with poly-D-lysine/laminin ( $400 \mu \mathrm{l} /$ well).

Cells were incubated in a $37^{\circ} \mathrm{C}$ incubator ( $5 \% \mathrm{CO} 2,95 \%$ humidity) (day 0 - D0). The medium was changed at D3. In order to understand, 
A

C
B

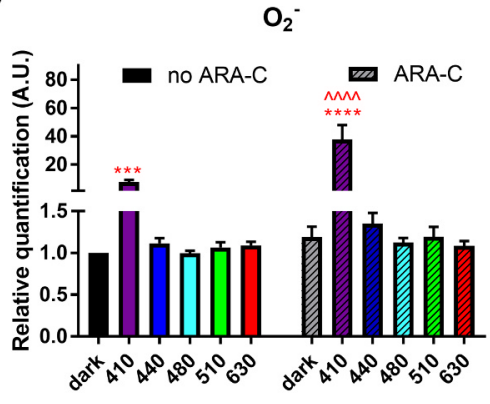

Wavelength $(\mathrm{nm})$

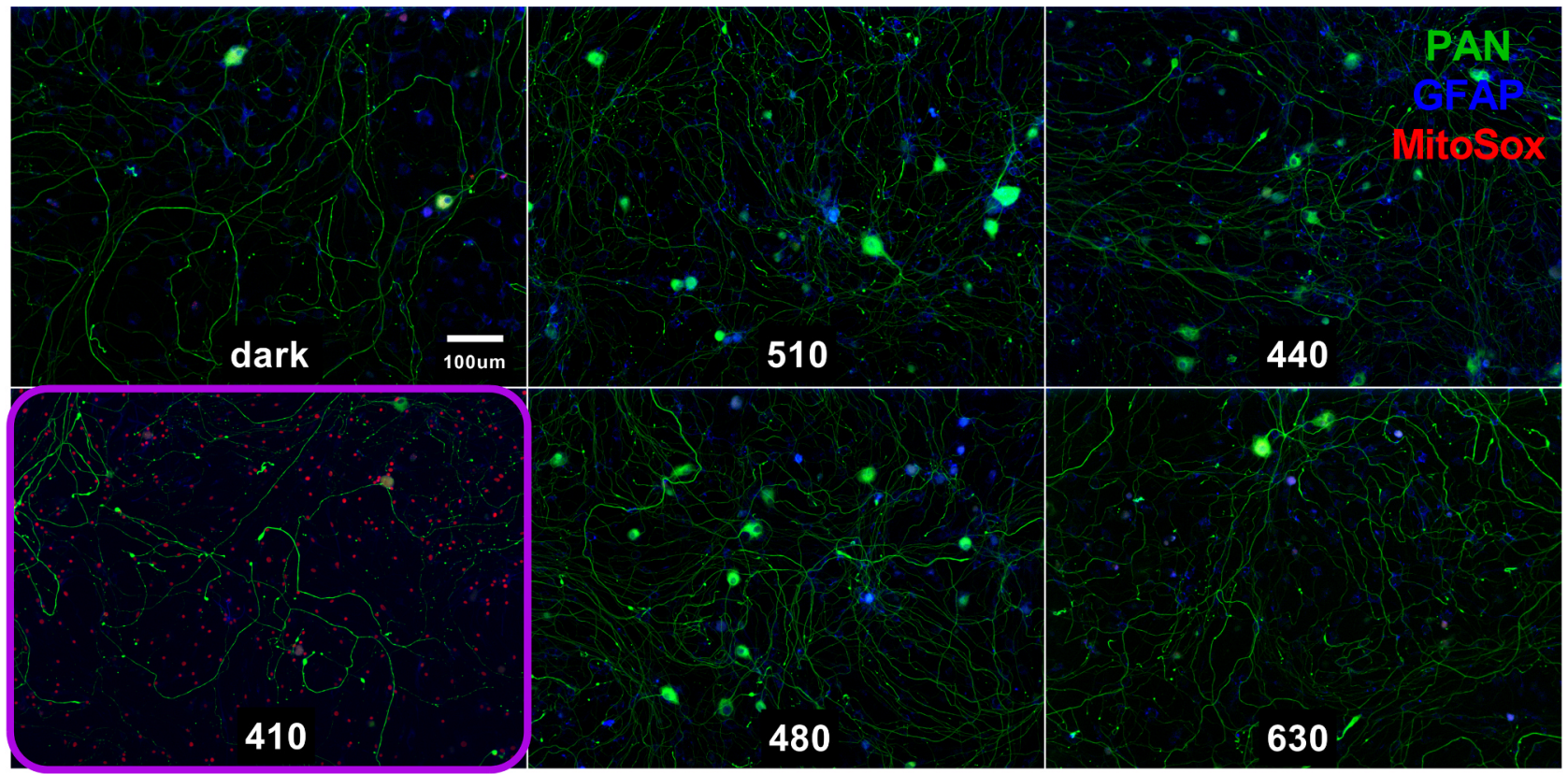

$E$

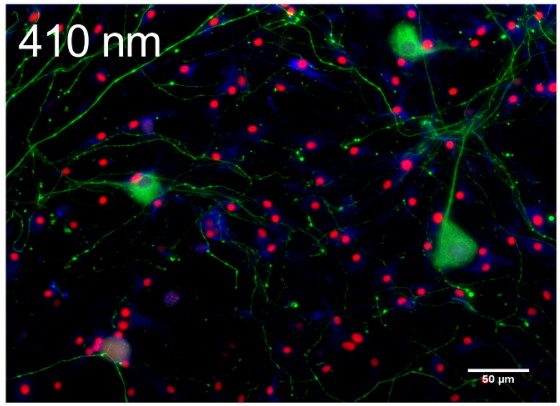

Glial part of $\mathrm{O}_{2}{ }^{-}$-stained cells (within every group)

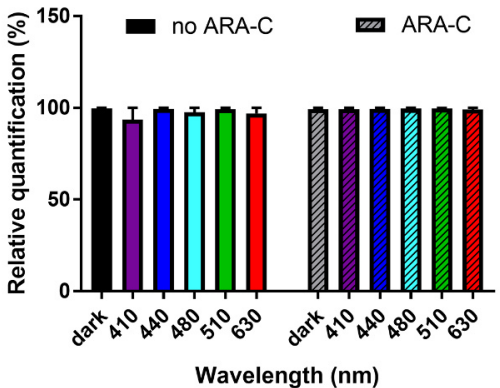

Fig. 3. Exposure to blue light induced oxidative stress. A,B. Measured rates of hydrogen peroxidase $(n=5)$ and superoxide anion $(n=3)$. C. Fluorescent images of $\mathrm{O}_{2}^{-}$- accumulation (red); cells were counterstained anti-PAN (green) and anti-GFAP (blue) antibody. Presented images correspond to AraC-treated culture. Scale bar represents $100 \mu \mathrm{m}$. Wells where the observed fluorescent signal was the most important is outlined in the color of the correspondent waveband. Numbers on wells indicate the correspondent light conditions (dark control or central wavelength). D. Zoom on a well exposed to $410 \mathrm{~nm}$ light $\left(\mathrm{O}_{2}{ }^{-{ }^{-}}\right.$- red, PAN - green, GFAP - blue) antibody. Scale bar represents $50 \mu \mathrm{m}$. E. Ratio between the number of cells presented red and blue fluorescent signals simultaneously (i.e., the number $\mathrm{O}_{2}{ }^{-}{ }^{-}$generating glial cells) and the number of all the red cells (i.e., the number of all the $\mathrm{O}_{2}{ }^{-{ }^{-}}$- generating cells) $(\mathrm{n}=4)$. Clear bars correspond to mixed and hatched bars to AraC-treated culture. Wavebands are represented by the correspondent colors; each $10 \mathrm{~nm}$ spectral band is designated by its central wavelength. Results shown represent the mean \pm SEM. Stars $\left(^{*}\right)$ refer to differences with the correspondent dark control within the same culture condition and carets $\left({ }^{\wedge}\right)$ refer to differences between culturing conditions (mixed vs. AraC) within the same light condition. Red signs correspond to an increase and blue signs to a decrease in values. Statistical significance: $\mathrm{p}<0.05(* /)), \mathrm{p}<0.01(* * / \mu), \mathrm{p}<0.001(* * * / \mu), \mathrm{p}<0.0001\left(* * * * /{ }^{\mu \wedge}\right)$. 
ATF3



IL6

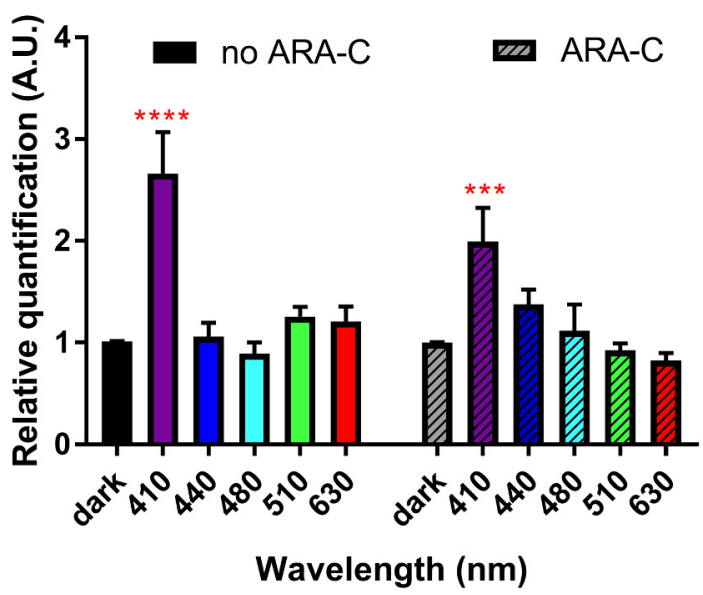

TGFb2

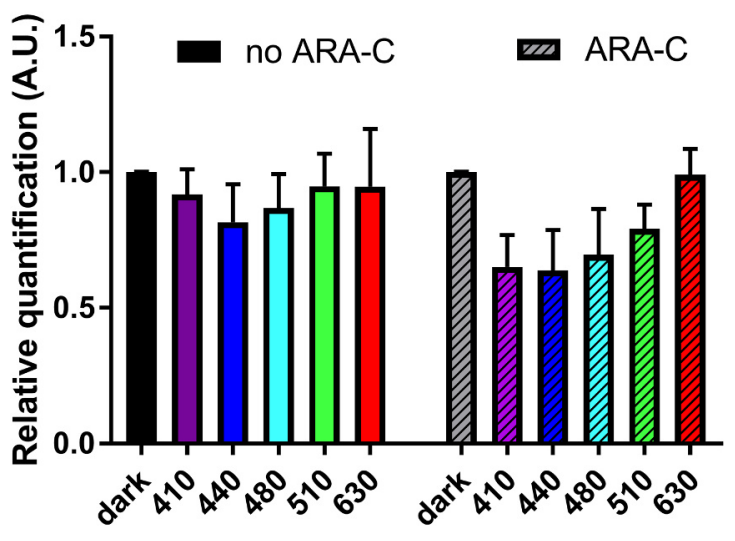

Wavelength $(\mathrm{nm})$

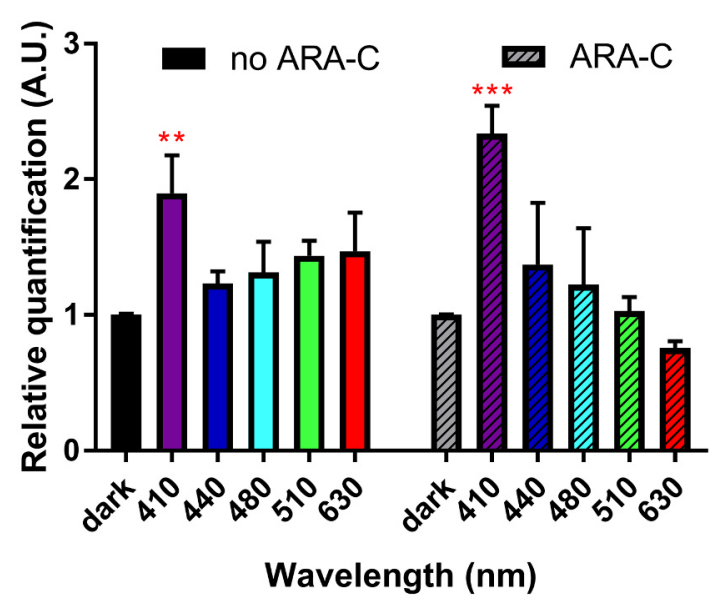

CCL2

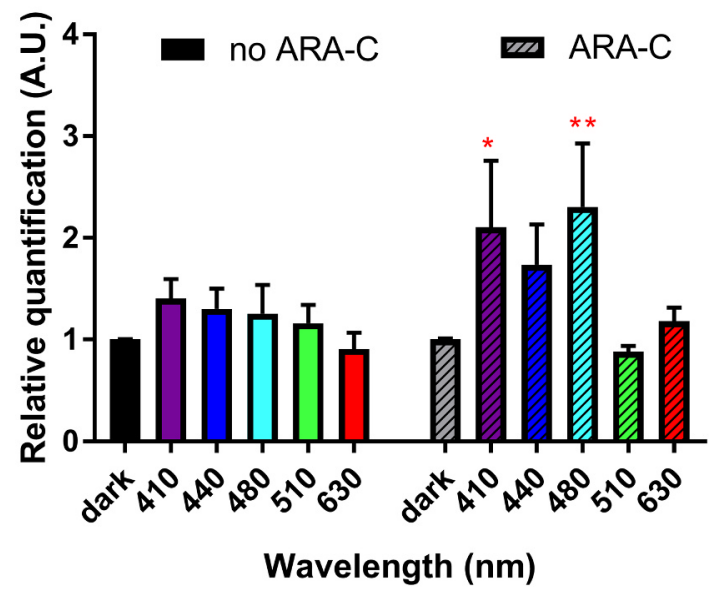

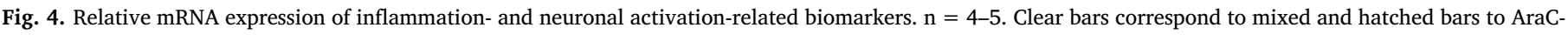

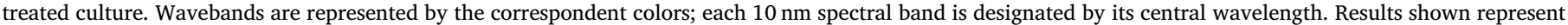

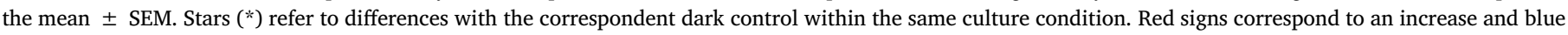
signs to a decrease in values. Statistical significance: $\mathrm{p}<0.05\left({ }^{*}\right), \mathrm{p}<0.01\left({ }^{* *}\right), \mathrm{p}<0.001\left({ }^{* *}\right), \mathrm{p}<0.0001\left(*^{* * *}\right)$.

whether the phototoxicity would depend on cell population, the medium was completed or not with AraC (Cytosine-1- $\beta$-D-arabinofuranoside) at $5 \mu \mathrm{M}$ to prevent glial cell proliferation $[27,33,65]$, to give mixed or AraC-treated culture, respectively. The medium was changed again at D7. Cells were illuminated at D10; the medium was replaced by fresh non-supplemented Neurobasal A without phenol red just before illumination.

Neurobasal-A without phenol red, FBS, B-27 minus AO, L-glutamine, penicillin and streptomycin were purchased from Gibco (Life technologies, Carlsbad, CA, USA); trypsin, collagenase A, DNAse, poly-D-lysine, 
A

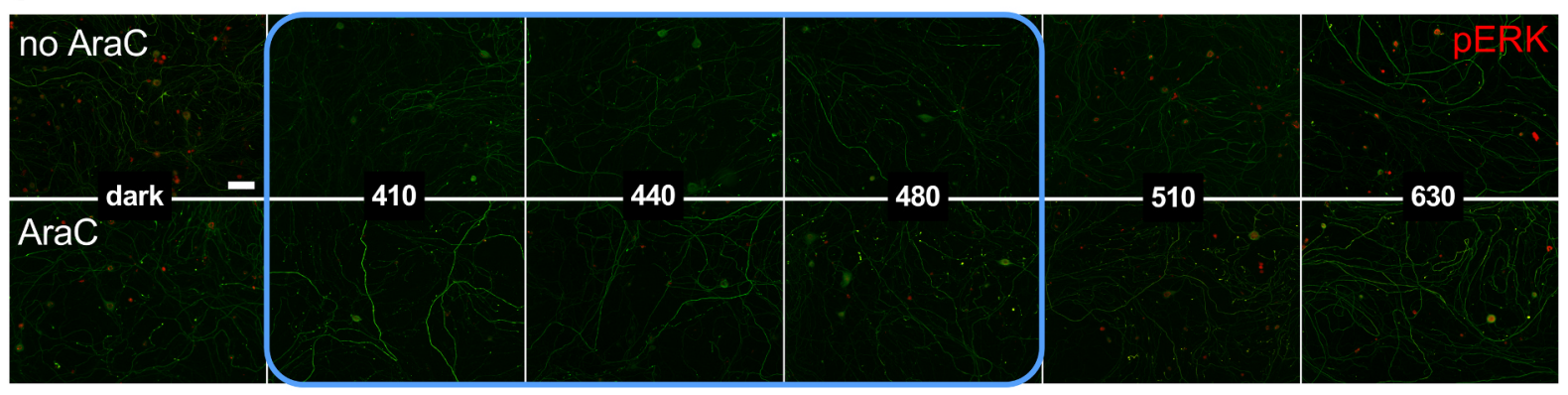

B

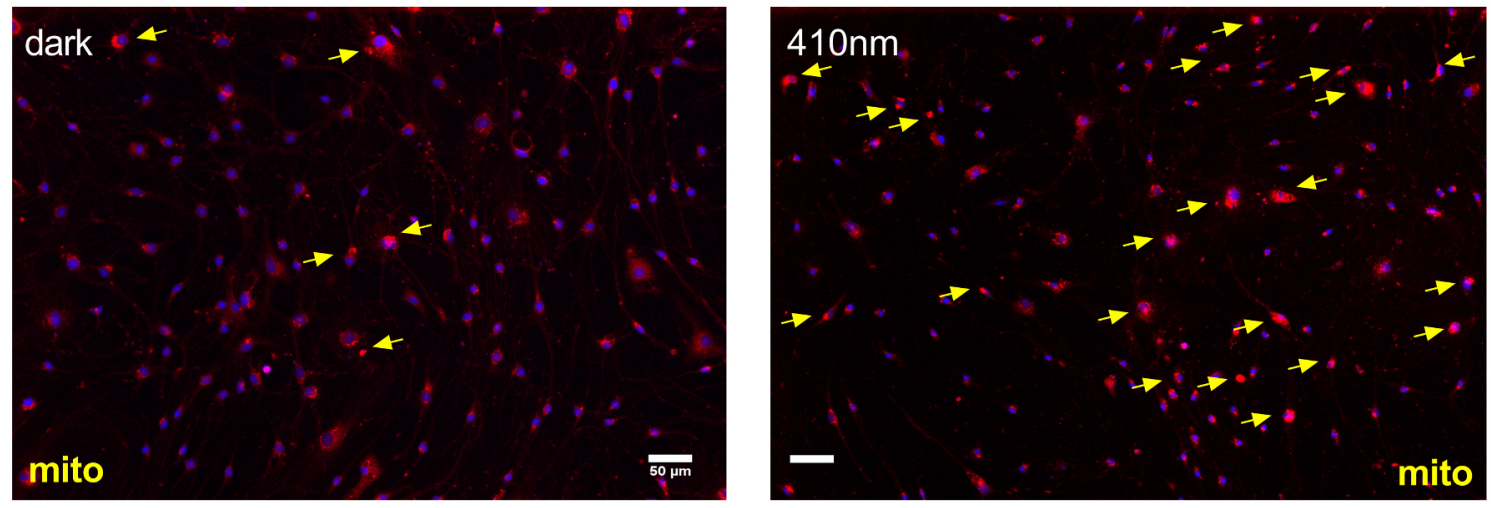

C

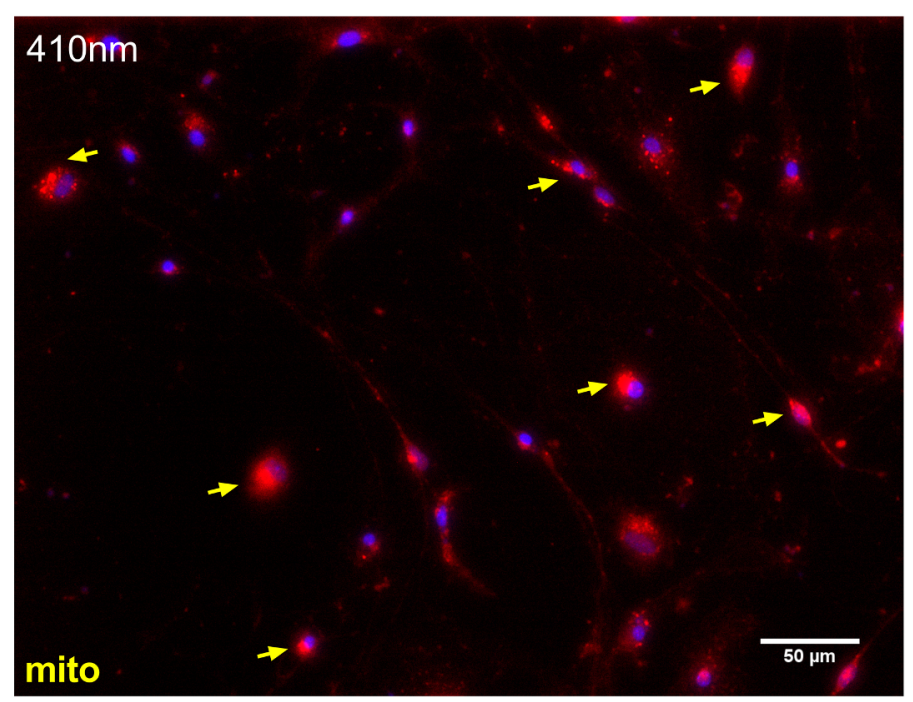

Fig. 5. Processing of blue-light phototoxic message. A. Immunostaining with anti-pERK (red) and anti-PAN (green) antibodies. Wells where the pERK fluorescent signal importantly decreased (as compared to dark control) or disappeared are outlined in blue. Numbers on wells indicate the correspondent light conditions (dark control or central wavelength). Scale bar represents $100 \mu \mathrm{m}$.

B,C. Immunostaining with mitochondria-tracking dye (red) and with DAPI (blue), in dark control or in 410-nm-illuminated wells (mixed culture). Arrows indicate accumulation of signal from compromised mitochondria. B corresponds to $10 \times$ and C corresponds to $20 \times$ magnification. Scale bars represent $50 \mu \mathrm{m}$.

laminin and AraC were purchased form Sigma Aldrich (St. Louis, MO, USA).

\subsection{Light emitting devices and protocol}

Cells were exposed to 5 various 10 -nm-wide light wavebands provided by a custom-made LED-based fibered device as described previously $[28,29]$. The central wavelengths of these wavebands were 410 , $440,480,510$ and $630 \mathrm{~nm}$; the irradiance was $1.1 \mathrm{~mW} / \mathrm{cm}^{2}$ except for the $630 \mathrm{~nm}$ waveband for which it was $1.53 \mathrm{~mW} / \mathrm{cm}^{2}$ (due to the illumination system limit) (Fig. S3). Irradiance level, spectral, and uniformity measurements were assessed using the calibrated spectroradiometer JAZ (Ocean Optics, Dunedin, USA). Cells in black 24 wellplate were illuminated for 3 hours; for each experiment, one subdivision of a well plate was maintained in dark (control cells). All the experiments to assess the light impact on cells were performed immediately after the end of light exposure. 


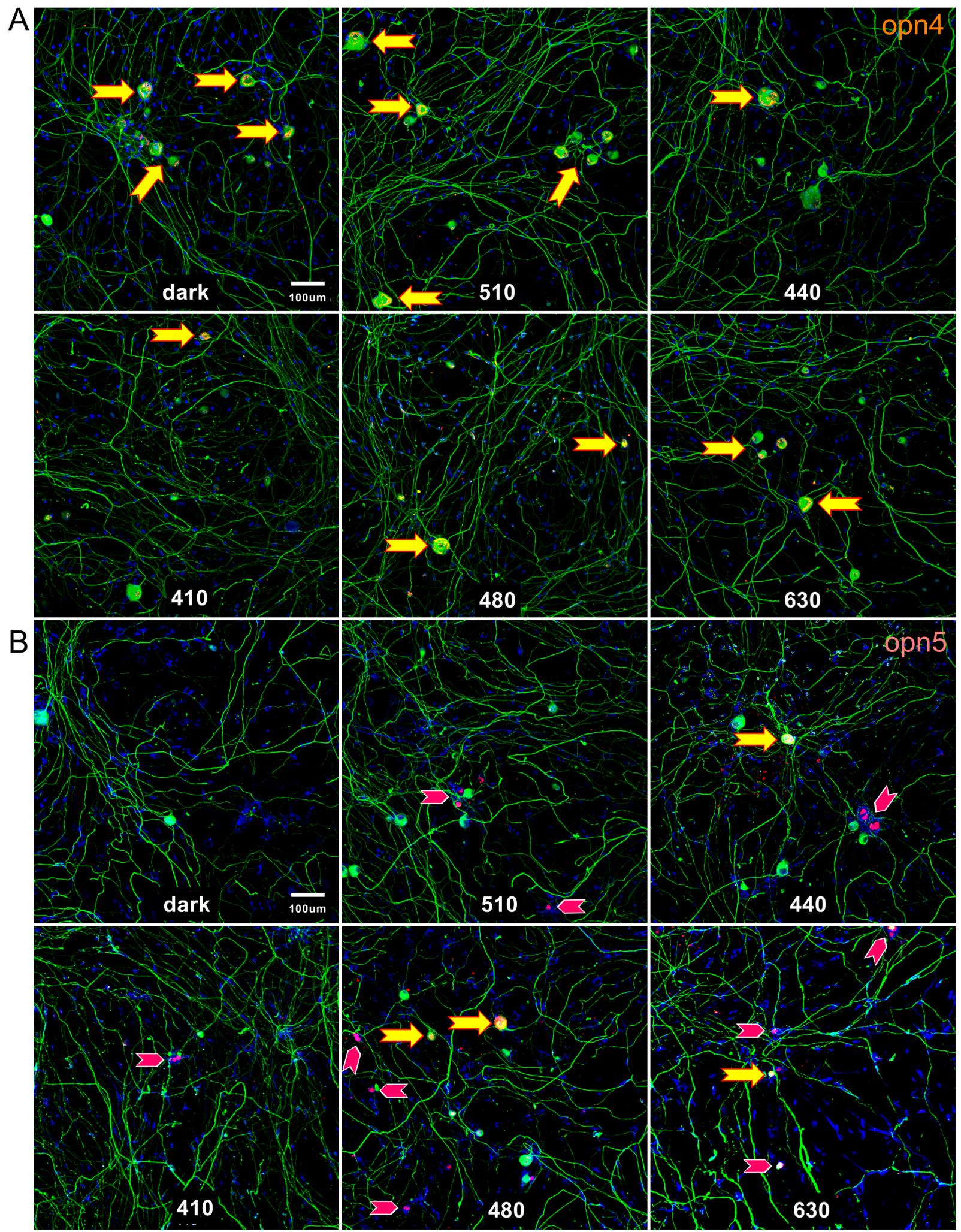

Fig. 6. Non-visual photoreception in trigeminal cells. A. Confocal images of immunostaining with anti-opn4 (red), anti-PAN (green) and DAPI (blue) antibodies (mixed culture). Arrows indicate melanospin-positive neurons. B. Confocal images of immunostaining with anti-opn5 (red), anti-PAN (green) and anti-GFAP (blue) antibodies (mixed culture). Neuropsin-positive cells are indicated by arrows, pink for glial cells and yellow for neurons. Numbers on wells indicate the correspondent light conditions (dark control or central wavelength). Scale bars represent $100 \mu \mathrm{m}$.

\subsection{Quantification of cell viability and $\mathrm{H}_{2} \mathrm{O}_{2}$ rate}

The CellTiter-Glo ${ }^{\circledR}$ Assay and the ROS-Glo ${ }^{\mathrm{TM}} \mathrm{H}_{2} \mathrm{O}_{2}$ Assay (Promega, Madison, WI, USA) were performed according to the manufacturer's protocol. Briefly, $\mathrm{H}_{2} \mathrm{O}_{2}$ Substrate Solution was added to cells before the light exposure. At the end of exposure, half of the supernatant of the illuminated well plate (plate N1) was carefully transferred to another well plate (plate N2), without touching the adherent cells. Then, the 
CellTiterGlo Detection Solution was added to the plate N1 and the ROSGlo Detection Solution was added to the plate N2. Both plates were incubated at room temperature (RT) in the dark for 20 min before luminescence reading on an Infinite M1000 microplate reader (Tecan, Männedorf, Switzerland). Luminescence values were normalized with respect to control cells (in the dark) in normal conditions considered as $100 \%$ viable. For $\mathrm{H}_{2} \mathrm{O}_{2}$ quantification (plate N2), the values were also normalized with respect to viability.

\subsection{Cell death assay - YO-PRO/PI staining}

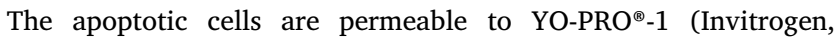
Eugene, Oregon, USA) while remaining non-permeable to Propidium Iodide (Interchim, Montluçon, France) which only stains necrotic cells $[66,67]$. The two reagents were mixed together in PBS (Gibco, Life technologies, Carlsbad, CA, USA) at the following concentrations: YOPRO - 1/150, PI - 1/15000. Such a mix was possible since the two dyes have different excitation/emission spectra. At the end of light exposure, the well plate was centrifuged at $1500 \mathrm{rpm}$ during $5 \mathrm{~min}$. Media were carefully replaced with $350 \mu \mathrm{l}$ of prepared solution; the well plate was then incubated for $30 \mathrm{~min}$ at RT in the dark. Further, $350 \mu \mathrm{l}$ of PBS were added to wells; the well plate was centrifuged again ( $1500 \mathrm{rpm}, 5 \mathrm{~min}$ ) and supernatants were replaced with $350 \mu$ lof fresh PBS. The fluorescent signals were read on an Infinite M1000 microplate reader (Tecan, Männedorf, Switzerland) in the following order, to avoid crossexcitations if there were any (hardly probable): YO-PRO $-\lambda \uparrow=491 \mathrm{~nm}$, $\lambda \downarrow=509 \mathrm{~nm}$; PI $-\lambda \uparrow=535 \mathrm{~nm}, \lambda \downarrow=617 \mathrm{~nm}$. Measured values were normalized with respect to control cells (in the dark) in normal conditions considered as 1 and also to viability. Cells were then fixed with 4\% paraformaldehyde-PBS (Sigma-Aldrich) and counterstained with DAPI, for further microscopic imaging.

\subsection{Quantification of $\mathrm{O}_{2}{ }^{-}$rate}

Superoxide anion levels were quantified using the MitoSOX ${ }^{\mathrm{TM}}$ Red Mitochondrial Superoxide Indicator dye (Life Technologies). MitoSOX reagent working solution $(5 \mu \mathrm{M})$ was prepared by diluting MitoSOX reagent stock solution ( $5 \mathrm{mM}$ in DMSO (Sigma Aldrich)) in Neurobasal A without phenol red buffer. At the end of light exposure, medium was replaced with $350 \mu \mathrm{l}$ of MitoSOX reagent working solution; the wellplate was then incubated for $10 \mathrm{~min}$ at $37^{\circ} \mathrm{C}$ in the dark. Cells were further carefully washed 3 times with warm PBS; $350 \mu$ of fresh PBS was added to wells. The fluorescent signal was read on an Infinite M1000 microplate reader (Tecan, Männedorf, Switzerland): $\lambda \uparrow$ $=510 \mathrm{~nm}, \lambda \downarrow=580 \mathrm{~nm}$. Measured values were normalized according to control cells (in the dark) in normal conditions considered as 1 and also according to viability. Cells were then fixed with $4 \%$ paraformaldehyde-PBS (Sigma-Aldrich) for further immunostaining and microscopic imaging.

\subsection{Immunostaining}

Fixed cells were incubated with blocking buffer (3\% NDS, $0.3 \%$ Triton) for $1 \mathrm{~h}$ and then stained with the following primary antibodies: mouse anti-PAN (EMD Millipore Corp., MAB2300, 1/1000), chicken anti-GFAP (Thermofisher, PA1-10004, 1/2000), mouse anti-GADD153 (Santa Cruz Biotechnology, sc-7351, 1/400), goat anti-p-ERK $1 \frac{1}{2}$ (the phosphorylated-ERK, the active form of the kinase) (Santa Cruz Biotechnology, sc-16982, 1/400), rabbit anti-opn4 (ATS, AB-N39, 1/ 500), rabbit anti-opn5 (Biorbyt, orb223499, 1/500). For anti-opn4 and -opn 5 stainings, cells were incubated with antibodies diluted in PBS for 2 nights at $4{ }^{\circ} \mathrm{C}$. Otherwise, antibodies were diluted in blocking buffer; incubation was done at RT for $1 \mathrm{~h}$. For revelation, cells were incubated with Alexa Fluor secondary antibodies (1:500 in PBS, Invitrogen) for $1 \mathrm{~h}$ at RT.

For all the immunostainings, negative control experiments (without incubation with a primary antibody) were performed, in order to ensure the absence of non-specific fluorescent signal.

\subsection{Mitochondrial status assessment}

Mitochondria status was assessed with MitoTracker ${ }^{\mathrm{TM}}$ Deep Red FM dye (Life Technologies, Carlsbad, CA, USA). MitoTracker reagent working solution $(25 \mu \mathrm{M})$ was prepared by diluting MitoSOX reagent stock solution (1 mM in DMSO (Sigma Aldrich, St. Louis, MO, USA)) in Neurobasal w/o phenol red buffer. At the end of light exposure, medium was replaced with $350 \mu \mathrm{l}$ of MitoTracker reagent working solution; the well-plate was then incubated for $30 \mathrm{~min}$ at RT in the dark. Cells were then fixed with 4\% paraformaldehyde-PBS (Sigma-Aldrich) and counterstained with DAPI, for further microscopic imaging.

\subsection{Imaging}

Cells were imaged with the inverted Nikon TiE microscope (image recording via Metamorph 7.7); images were then processed with the Fiji software (ImageJ version).

For high-content quantitative analysis based on immunostainings with anti-PAN and anti-GFAP antibodies as well as with MitoSOX ${ }^{\mathrm{TM}}$ Red Mitochondrial Superoxide Indicator dye, cells were imaged with an automated microscope Thermo-Cellomics Arrayscan (Thermofisher, Waltham, MA, USA). Images were then analyzed by system-provided algorithms (Neuronal Profiling and Target Activation bioapplications of Visual Studio software) to evaluate cell number, cell area, neurite length and DAPI-staining intensity. For each well (of $1.9 \mathrm{~cm}^{2}$ total surface), a central part of $0.81 \mathrm{~cm}^{2}$ surface was analyzed (this corresponded to 81 scanned fields of $1002 \mu \mathrm{m}$ side each).

Imaging of anti-melanopsin and anti-neurosin immunostainings were performed on an Olympus FV1200 laser-scanning confocal microscope (Olympus, Rungis, France). DAPI, AlexaFluor-594, AlexaFluor-647 and AlexaFluor-488 were excited by using 405, 559 and $635 \mathrm{~nm}$ laser diodes lines and $488-515 \mathrm{~nm}$ argon ion laser lines, respectively. The objective used was an UPLSAPO 20X NA 0.85-WD 0.20.

Identical exposure settings, that minimized oversaturated pixels in the final images, were used for each illumination condition.

\section{9. $R T-q P C R$}

After the end of illumination, cells were washed and lysed; total RNA was extracted using a NucleoSpin RNA XS extraction kit (Macherey-Nagel, Düren, Germany) according to the provided protocol. RNA quality and quantity were assessed using a ND-1000 spectrophotometer (Thermo Scientific, Waltham, Massachusetts, USA). cDNA was further synthesized from equal amounts of RNA using Multiscribe reverse transcriptase (TaqMan Reverse Transcription Reagents, Applied Biosystems, Life Technologies, Carlsbad, CA, USA) according to the manufacturer's protocol. Finally, cDNA were diluted in DNAse/RNAse free water (Gibco) to a final concentration of $2 \mathrm{ng} / \mu \mathrm{l}$. Real-time quantitative PCR was performed with $10 \mathrm{ng}$ of cDNA added to a $15 \mu \mathrm{l}$ solution of Applied Biosystems Mastermix (TaqMan Universal PCR Master Mix) and primers to a final volume of $20 \mu \mathrm{l}$. All primers and reagents were purchased from Applied Biosystems: GAPDH (Mm99999915_m1), ATF3 (Mm00476033_m1), cFOS (Mm00487425_m1), IL6 (Mm00446190_m1), CCL2 (Mm00441242_m1), TGFß2 (Mm00436955_m1). Target cDNA was amplified using the 7300 RealTime PCR system (Applied Biosystems). Changes in mRNA expression were calculated as $\Delta \Delta \mathrm{Ct}=\Delta \mathrm{Ct}_{\text {illuminated }}-\Delta \mathrm{Ct}_{\text {control }}$ with $\Delta \mathrm{Ct}$ $=\mathrm{Ct}_{\text {target_gene }}-\mathrm{Ct}_{\mathrm{HK} \_ \text {gene. }} \mathrm{Ct}$ means cycle threshold and HK_gene means housekeeping gene (GAPDH). Since the application of antimitotic treatment changed the cell population and therefore the expression of house-keeping genes, we did not compare the mRNA levels between mixed culture and the one with AraC. The calculation was done for each group (mixed culture or AraC-treated culture) separately; non- 
illuminated cells within every group were taken as controls.

\subsection{Statistical analysis}

All experiments were repeated at least three times in technical replicate (the exact number of performed experiments is specified in the legends of the corresponding figures). Statistical analyzes were performed using GraphPad (GraphPad Software, La Jolla, CA, USA). Twoway ANOVA analysis with non-repeated measures followed by False Discovery Rate multiple correction (two-stage step-up method of Benjamini, Krieger and Yekutieli, false discovery rate $q=0.05$ ) were used. All data are presented as mean \pm SEM. Values given in the Results section were rounded to the second decimal digit to facilitate the reading. When not specified, the corresponding $\mathrm{p}$ and $\mathrm{q}$ values were given for the comparison with the respective dark control (within the same AraC or non-AraC group). Differences were considered significant when $\mathrm{p}<0.05(* / \wedge), \mathrm{p}<0.01(* * / \wedge), \mathrm{p}<0.001(* * * / \mu)$ or $\mathrm{p}<0.0001(* * * * / \mu n n)$.

\section{Acknowledgements}

We are grateful to Fanny Montoya for implementation of preliminary experiments. We thank Coralie Barrau and Camille Ehrismann for technical support of the illumination systems and Stéphane Fouquet for the support of imaging facility. We also thank the cell culture, imaging and HTS platforms at the Institut de la Vision (Paris).

\section{Sources of funding}

This work was funded by Essilor International, France, within the frame of research collaboration with Sorbonne Université and Institut de la Vision (Paris).

\section{Conflict of interest}

$\mathrm{VM}$ and TV are Essilor employees. AP, AR, ER, AC, CB, WR, AD, and SM declare no competing interests.

\section{Appendix A. Supplementary material}

Supplementary data associated with this article can be found in the online version at doi:10.1016/j.freeradbiomed.2018.11.029.

\section{References}

[1] J. Marshall, Understanding risks of phototoxicity on the eye [Internet], Point de Vue, International Review of Ophthalmic Optics, 2014. [cited 2017 Nov 7]. Available from: $\langle$ http://www.pointsdevue.com/article/understanding-risksphototoxicity-eye $\rangle$.

[2] Text Request, How Much Time Do People Spend on Their Mobile Phones in 2017? [Internet], Hackernoon. [cited 2017 Nov 7]. Available from: 〈https://hackernoon. com/how-much-time-do-people-spend-on-their-mobile-phones-in-2017e5f90a0b10a6>.

[3] J. Lupis, The State of Traditional TV: Updated With Q1 2017 Data [Internet]. Mareketing charts, [cited 2017 Nov 7]. Available from: 〈http://www. marketingcharts.com/featured-24817>.

[4] K. Digre, K.C. Brennan, Shedding light on photophobia, J. Neuroophthalmol. 32 (1) (2012) 68-81.

[5] B.J. Katz, K.B. Digre, Diagnosis, pathophysiology, and treatment of photophobia, Surv. Ophthalmol. (2016) 466-477, https://doi.org/10.1016/j.survophthal.2016. 02.001.

[6] Y. Wu, M. Hallett, Photophobia in neurologic disorders [Internet], Transl. Neurodegener. 6 (1) (2017) 26 (Available from: 〈http:// translationalneurodegeneration.biomedcentral.com/articles/10.1186/s40035-017 0095-3 >).

[7] F. Stapleton, M. Alves, V.Y. Bunya, I. Jalbert, K. Lekhanont, F. Malet, et al., The ocular surface TFOS DEWS II epidemiology report, Ocul. Surf. (2017) 334-365, https://doi.org/10.1016/j.jtos.2017.05.003.

[8] A. Yazici, E.S. Sari, G. Sahin, A. Kilic, H. Cakmak, O. Ayar, et al., Change in tear film characteristics in visual display terminal users, EJO 25 (2) (2015) 85-89.

[9] M. Kaido, I. Toda, T. Oobayashi, M. Kawashima, Reducing short-wavelength blue light in dry eye patients with unstable tear film improves performance on tests of visual acuity, PLoS One 11 (4) (2016) 1-10, https://doi.org/10.1371/journal.pone. 0152936.

[10] R. Courtin, B. Pereira, G. Naughton, A. Chamoux, F. Chiambaretta, C. Lanhers, et al., Prevalence of dry eye disease in visual display terminal workers: a systematic review and meta-analysis, BMJ (2016).

[11] M. Uchino, N. Yokoi, Y. Uchino, M. Dogru, M. Kawashima, A. Komuro, et al., Prevalence of dry eye disease and its risk factors in visual display terminal users: The Osaka study, Am. J. Ophthalmol. (2013) 759-766, https://doi.org/10.1016/j. ajo.2013.05.040.

[12] A.P. Cullen, Photokeratitis and other phototoxic effects on the cornea and conjunctiva, Int. J. Toxicol. (2002) 455-464 (Spring/Primavera).

[13] J. Voke Radiation effects on the eye, Part 3a - Ocular effects of ultraviolet radiation. Optom Today [Internet], 1999, pp. 27-32. Available from: 〈http://www. optometry.co.uk/pages/articles/articles1999.php\%5CnC:\%5CLibrary \%5CVoke1999.pdf>.

[14] P.L. Turner, E.J.W. Van Someren, M.A. Mainster, The role of environmental light in sleep and health: effects of ocular aging and cataract surgery, Sleep Med. Rev. (2010) 269-280, https://doi.org/10.1016/j.smrv.2009.11.002.

[15] J. Voke, Radiation effects on the eye. Part 3b - ocular effects of ultraviolet radiation, Optom. Today (1999) 37-41.

[16] A. Krigel, M. Berdugo, E. Picard, R. Levy-Boukris, I. Jaadane, L. Jonet, et al., Lightinduced retinal damage using different light sources, protocols and rat strains reveals LED phototoxicity, Neurosci. IBRO 339 (2016) 296-307, https://doi.org/10. 1016/j.neuroscience.2016.10.015.

[17] V. Marek, S. Mélik-parsadaniantz, T. Villette, F. Montoya, C. Baudouin, F. BrignoleBaudouin, et al., Blue light phototoxicity toward human corneal and conjunctival epithelial cells in basal and hyperosmolar conditions, Free Radic. Biol. Med. (2018), https://doi.org/10.1016/j.freeradbiomed.2018.07.012.

[18] J. Lee, S. Kim, S. Lee, H. Kim, H. Ahn, Z. Li, Blue light - induced oxidative stress in human corneal epithelial cells: protective effects of ethanol extracts of various medicinal plant mixtures, Cornea 55 (7) (2014) 4119-4127.

[19] M. Ayaki, Y. Niwano, T. Kanno, K. Tsubota, Blue light induces oxidative damage in human ocular surface cells in culture, ARVO 2015 Annu Meet. Abstr. (2015).

[20] Y. Niwano, T. Kanno, A. Iwasawa, M. Ayaki, K. Tsubota, Blue light injures corneal epithelial cells in the mitotic phase in vitro, Br. J. Ophthalmol. 98 (7) (2014) 990-992 (Available from 〈http://www.ncbi.nlm.nih.gov/pubmed/24682182 〉)

[21] Hwang H. Bin, Kim, H.S. Phototoxic, effects of an operating microscope on the ocular surface and tear film, Cornea 33 (1) (2014) 82-90 (Available from 〈http:// www.ncbi.nlm.nih.gov/pubmed/24310622 >).

[22] T. Ipek, M.P. Hanga, A. Hartwig, J. Wolffsohn, C. O'Donnell, Dry eye following cataract surgery: the effect of light exposure using an in-vitro model, Contact Lens Anterior Eye (2017) 3-6 (Available from 〈http://linkinghub.elsevier.com/retrieve/ $\mathrm{pii} / \mathrm{S} 1367048417302370>)$.

[23] A. Albilali, E. Dilli, Photophobia: when light hurts, a review, Curr. Neurol. Neurosci. Rep. Curr. Neurol. Neurosci. Rep. 18 (62) (2018) 4-9.

[24] A. Réaux-le-Goazigo, A. Labbé, C. Baudouin, Stéphane Melik-Parsadaniantz, La douleur oculaire chronique: mieux la comprendre pour mieux la traiter, Med./Sci. 33 (2017) 749-757.

[25] C. Belmonte, A. Aracil, C. Acosta, C. Luna, J. Gallar, Nerves and sensations from the eye surface, Ocul. Surf. 2 (4) (2004) 248-253.

[26] A. Matynia, E. Nguyen, X. Sun, F.W. Blixt, S. Parikh, J. Kessler, et al., Peripheral sensory neurons expressing Melanopsin respond to, Front Neurql Circuits 10 (2016) $1-15$.

[27] P. Launay, E. Reboussin, H. Liang, K. Kessal, D. Godefroy, W. Rostène, et al., Neurobiology of Disease Ocular in flammation induces trigeminal pain, peripheral and central neuroinflammatory mechanisms, Neurobiol. Dis. 88 (2016) 16-28.

[28] M. Marie, K. Bigot, C. Angebault, C. Barrau, P. Gondouin, D. Pagan, et al., Light action spectrum on oxidative stress and mitochondrial damage in A2E-loaded retinal pigment epithelium cells, Cell Death Dis. (2018), https://doi.org/10.1038/ s41419-018-0331-5.

[29] E. Arnault, C. Barrau, P. Gondouin, K. Bigot, T. Villette, S. Picaud, et al., Phototoxic action spectrum on a retinal pigment epithelium model of age-related macular degeneration exposed to sunlight normalized conditions, PLoS One 8 (8) (2013).

[30] T.A. Legates, D.C. Fernandez, S. Hattar, Light as a central modulator of circadian rhythms, sleep and affect, Nat. Rev. Neurosci. 15 (7) (2014) 443-454.

[31] R.-R. Nir, R. Noseda, C. Bernstein, C. Buettner, A.B. Fulton, S.M. Bertisch, et al., Color-selective photophobia in Ictal vs. Interictal Migraineurs and in healthy controls, Pain (2018).

[32] R. Noseda, C.A. Bernstein, R. R. Nir, A.J. Lee, A.B. Fulton, S.M. Bertisch, et al, Migraine photophobia originating in cone-driven retinal pathways, Brain 139 (7) (2016) 1971-1986.

[33] D. Godefroy, R.D. Gosselin, A. Yasutake, M. Fujimura, C. Combadie're, R. MauryBrachet, et al., The chemokine CCL2 protects against methylmercury neurotoxicity, Toxicol. Sci. 125 (1) (2012) 209-218.

[34] S. Kim, H.-S. Cheon, S.-Y. Kim, Y.-S. Juhnn, Y.-Y. Kim, Cadmium induces neuronal cell death through reactive oxygen species activated by GADD153, BMC Cell Biol. 14 (1) (2013) 4, https://doi.org/10.1186/1471-2121-14-4 (Available from 〈http:// bmccellbiol.biomedcentral.com/articles/ $>$ ).

[35] R.M. Silva, V. Ries, T.F. Oo, O. Yarygina, V. Jackson-Lewis, E.J. Ryu, et al., CHOP/ GADD153 is a mediator of apoptotic death in substantia nigra dopamine neurons in an in vivo neurotoxin model of parkinsonism, J. Neurochem. 95 (4) (2005) 974-986.

[36] S.K. Ward, T.H. Wakamatsu, M. Dogru, O.M.A. Ibrahim, M. Kaido, Y. Ogawa, et al., The role of oxidative stress and inflammation in dry eye disease, Cornea 28 (9) (2009) 70-74.

[37] T.H. Wakamatsu, M. Dogru, K. Tsubota, Tearful relations: oxidative stress, 
inflammation and eye diseases, Arq. Bras. Oftalmol. 2 (7) (2008) 72-79.

[38] I. Jaadane, P. Boulenguez, S. Chahory, S. Carré, M. Savoldelli, L. Jonet, et al., Retinal damage induced by commercial Light Emitting Diodes (LED), Free Radic Biol. Med. (2015).

[39] G.P. Bienert, J.K. Schjoerring, T.P. Jahn, Membrane transport of hydrogen peroxide, Biochim Biophys. Acta - Biomembr. 1758 (8) (2006) 994-1003 (Available from 〈http://linkinghub.elsevier.com/retrieve/pii/S0005273606000472 〉).

[40] Y. Luo, D.B. DeFranco, Opposing roles for ERK1/2 in neuronal oxidative toxicity: distinct mechanisms of ERK1/2 action at early versus late phases of oxidative stress, J. Biol. Chem. 281 (24) (2006) 16436-16442.

[41] G.Y. Li, T. Li, B. Fan, Y.C. Zheng, T.H. Ma, The D1 dopamine receptor agonist, SKF83959, attenuates hydrogen peroxide-induced injury in RGC-5 cells involving the extracellular signal-regulated kinase/p38 pathways, Mol. Vis. 18 (2012) 2882-2895 (Available from 〈http://www.ncbi.nlm.nih.gov/pubmed/23233790\% 5Cnhttp://www.ncbi.nlm.nih.gov/pmc/articles/PMC3519376/pdf/mv-v18-2882. pdf $>$ ).

[42] Y. Kuse, K. Ogawa, K. Tsuruma, M. Shimazawa, H. Hara, Damage of photoreceptorderived cells in culture induced by light emitting diode-derived blue light, Sci. Rep. 4 (5223) (2014) 1-12.

[43] A. Denoyer, D. Godefroy, I. Celerier, J. Frugier, L. Riancho, F. Baudouin, et al, CX3CL1 expression in the conjunctiva is involved in immune cell trafficking during toxic ocular surface inflammation, Mucosa Immunol. 5 (6) (2012) 703-711.

[44] N. Deschamps, C. Baudouin, Dry eye and biomarkers: present and future, Curr. Ophthalmol. Rep. (2013) 65-74.

[45] C. Dauvergne, J. Molet, A.R. Goazigo, A. Mauborgne, Y. Boucher, Implication of the chemokine CCL2 in trigeminal nociception and traumatic neuropathic orofacial pain, Eur. J. Pain. 18 (2014) 360-375.

[46] J. Van Steenwinckel, C. Auvynet, A. Sapienza, A. Reaux-Le Goazigo, C. Combadière, S. Melik Parsadaniantz, Stromal cell-derived CCL2 drives neuropathic pain states through myeloid cell infiltration in injured nerve, Brain Behav. Immun. (2015) 198-210, https://doi.org/10.1016/j.bbi.2014.10.016.

[47] S. Saika, TGFß pathobiology in the eye, Lab Investig. 86 (2) (2006) 106-115.

[48] E.A. Meyers, J.A. Kessler, TGF-b family signaling in neural and neuronal differentiation, development, and function, Cold Spring Harb. Perspect. Biol. 9 (8) (2017) $1-26$.

[49] S. Sanjabi, L.A. Zenewicz, M. Kamanaka, R.A. Flavell, Anti- and pro-inflammatory roles of TGF- $\beta$, IL-10, and IL-22 in immunity and autoimmunity, Curr. Opin. Pharmacol. 9 (4) (2009) 447-453.

[50] E. Bullitt, Expression of C-fos-like protein as a marker for neuronal activity following noxious stimulation in the rat, J. Comp. Neurol. (1990) 517-530, https:// doi.org/10.1002/cne.902960402 (Available from: 〈http://www.ncbi.nlm.nih.gov/ pubmed/2113539\%5Cn >).

[51] D. Hunt, G. Raivich, P.N. Anderson, Activating transcription factor 3 and the nervous system, Front. Mol. Neurosci. 5 (2012) 1-17, https://doi.org/10.3389/fnmol. 2012.00007/abstract (Available from 〈http://journal.frontiersin.org/article/〉).

[52] B.F. Godley, F.A. Shamsi, F.-Q. Liang, S.G. Jarrett, S. Davies, M. Boulton, Blue light induces mitochondrial DNA damage and free radical production in epithelial cells, J. Biol. Chem. 280 (22) (2005) 21061-21066, https://doi.org/10.1074/jbc.
M502194200 (Available from 〈http://www.jbc.org/lookup/doi/ 〉).

[53] G. Lascaratos, D. Ji, J.P.M. Wood, N.N. Osborne, Visible light affects mitochondria function and induces neuronal death in retinal cell cultures, Vis. Res. 47 (9) (2007) 1191-1201.

[54] A. Delwig, S.Y. Chaney, A.S. Bertke, J. Verweij, S. Quirce, D.D. Larsen, et al., Melanopsin expression in the cornea, Vis. Neurosci. (2018) 35

[55] E.D. Buhr, W.W.S. Yue, X. Ren, Z. Jiang, H.R. Liao, X. Mei, et al., Circadian oscillators in mammalian retina and cornea, PNAS 7 (2015) 1-6.

[56] M.E. Guido, P.S. Nieto, D.J. Valdez, V.A. Acosta-rodrı, Expression of novel opsins and intrinsic light responses in the mammalian retinal ganglion cell line RGC-5. Presence of OPN5 in the rat retina, PLoS One 6 (2011) 10

[57] P.S. Launay, D. Godefroy, H. Khabou, W. Rostene, J.A. Sahel, C. Baudouin, et al., Combined 3DISCO clearing method, retrograde tracer and ultramicroscopy to map corneal neurons in a whole adult mouse trigeminal ganglion, Exp. Eye Res. 139 (2015) 136-143.

[58] ThermoFisher Scientific, Membrane Potential Indicators [Internet]. [cited $2018 \mathrm{Jul}$ 19]. Available from: 〈https://www.thermofisher.com/fr/en/home/life-science/ cell-analysis/cell-viability-and-regulation/ion-indicators/membrane-potentialindicators.html $>$.

[59] A. Hamberger, C. Blomstrand, A.L. Lehninger, Comparative studies on mitochondria isolated from neuron-enriched and glia-enriched fractions of rabbit and beef brains, J. Cell Biol. 45 (1970) 221-234.

[60] A.J. Tolani, G.P. Talwar, Differential metabolism of various brain regions, Biochem. J. 88 (1960) (1962) 357-362.

[61] T. Matsuyama, T. Yamashita, Y. Imamoto, Y. Shichida, Photochemical properties of mammalian melanopsin, Biochemistry 51 (27) (2012) 5454-5462.

[62] P. Newsholme, E. Rebelato, F. Abdulkader, M. Krause, A. Carpinelli, R. Curi, Reactive oxygen and nitrogen species generation, antioxidant defenses, and b-cell function: a critical role for amino acids, J. Endocrinol. 214 (2012) 11-20.

[63] T. Konno, E.P. Melo, C. Lopes, I. Mehmeti, S. Lenzen, D. Ron, et al., ERO1-independent production of $\mathrm{H}_{2} \mathrm{O}$ within the endoplasmic reticulum fuels $\mathrm{Prdx} 4$ mediated oxidative protein folding, J. Cell Biol. 211 (2) (2015) 253-259.

[64] Z. Liu, Y. Lv, N. Zhao, G. Guan, J. Wang, Protein kinase R-like ER kinase and its role in endoplasmic reticulum stress-decided cell fate, Cell Death Dis. 6 (7) (2015) 1-10.

[65] T. Djogo, S.C. Robins, S. Schneider, D. Kryzskaya, X. Liu, A. Mingay, et al., Adult NG2-Glia are required for median eminence-mediated leptin sensing and body weight control, Cell Metab. (2016) 797-810, https://doi.org/10.1016/j.cmet.2016. 04.013.

[66] M. Dutot, H. Liang, T. Pauloin, F. Brignole-Baudouin, C. Baudouin, J.-M. Warnet, et al., Effects of toxic cellular stresses and divalent cations on the human P2 $\times 7$ cell death receptor, Mol. Vis. 14 (2008) 889-897 (Available from 〈http://www.ncbi. nlm.nih.gov/pubmed/18490962\%5Cnhttp://www.pubmedcentral.nih.gov/ articlerender.fcgi?artid $=$ PMC2386509 $>$ ).

[67] C. Mehanna, C. Baudouin, F. Brignole-Baudouin, Spectrofluorometry assays for oxidative stress and apoptosis, with cell viability on the same microplates: a multiparametric analysis and quality control, Toxicol. Vitr. (2011) 1089-1096, https:// doi.org/10.1016/j.tiv.2011.03.007. 